IFN Working Paper No. 670, 2006

\title{
Entrepreneurial Innovations, Competition and Competition Policy
}

Per-Johan Norbäck and Lars Persson 


\title{
Entrepreneurial Innovations, Competition and Competition Policy
}

\author{
Pehr-Johan Norbäck* \\ Research Institute of Industrial Economics \\ Lars Persson \\ Research Institute of Industrial Economics and CEPR
}

May 5, 2010

\begin{abstract}
We construct a model where an entrepreneur could innovate for entry or for sale. It is shown that increased product market competition tends to increase the relative profitability of innovation for sale. Increased competition reduces entrants' and acquirers' profits in a similar fashion, but also reduces the profit of non-acquirers. Therefore, incumbents' valuations of innovations are less negatively affected by increased competition, and the incentive for innovation for sale can increase with increased competition. Moreover, a stricter, but not too strict, merger policy is shown to increase the incentive for innovations for sale by ensuring the bidding competition for the innovation.
\end{abstract}

\footnotetext{
${ }^{*}$ We have benefitted from useful comments from Daron Acemoglu, Philippe Aghion, Catherine Casamatta, Mattias Ganslandt, Henrik Horn, Dan Kovenock, Kevin Murphy, Jonas Vlachos and participants in seminars at the CEPR/IUI Workshop on Innovation, Ownership and Competition in Stockholm, Universidade Católica Portuguesa, RICAF2 Second Conference in Riga, and Stockholm School of Economics. Financial support from the Marianne and Marcus Wallenberg Foundation and Tom Hedelius' and Jan Wallander's Research Foundation is gratefully acknowledged. This paper was written within the Gustaf Douglas Research Program on Entrepreneurship. Email: lars.persson@ifn.se
} 


\section{Introduction}

Entrepreneurial innovations, i.e. innovations made by outsiders to a specific industry, constitute a crucial ingredient in a well-functioning market economy. ${ }^{1}$ Increased competition is generally perceived as beneficial for the functioning of a market; however, there are some concerns that the incentives for entrepreneurial innovations can be reduced when product market competition is too strong and hence, the rents accruing to the innovator are too small. This argument is well established in the case where an entrepreneurial innovator commercializes the invention herself. $^{2}$ However, entrepreneurs could also sell their innovation (business) to incumbents and we indeed observe a significant amount of inter-firm technology transfers, ranging from joint ventures and licensing to outright acquisitions of innovations. ${ }^{3}$ The purpose of this paper is to study the impact of increased product market competition and strengthened competition policy on the incentives for and the pattern of innovation for sale and innovation for entry.

To this end, we construct a model with the following ingredients: Initially, the intensity of competition in an oligopolistic product market is determined by nature or policy. An entrepreneur then invests in an innovative activity that could lead to the creation of a unique productive asset, which increases the profit of the possessor and decreases the profits of the rival firms. If successful, the entrepreneur could then either sell the innovation to one of the incumbents in an auction acquisition game or enter the product market.

We take our starting point in the fact that many of the formalizations of the intensity of product market competition used in the literature, such as an increased number of firms in an industry, lower entry costs, and increased substitutability between products, reduce the short-run product market profits. ${ }^{4}$ Our first result then establishes that increased intensity of competition tends to increase the profitability of innovation for sale relative to innovation for entry. The reason for this is that increased intensity of competition reduces entrants' and acquirers' profits in a similar fashion, but also reduces the profit when not acquiring. This implies that the incumbent's willingness to pay for the innovation is less negatively affected and thus, the entrepreneur benefits from selling the innovation instead of entering the market.

Then, we turn to how the intensity of competition affects the incentive to innovate. First,

${ }^{1}$ See, for instance, Acs and Audretsch (2005) and Baumol (2002) for such evidence.

2 This argument dates back at least to Schumpeter (1912) and since then, it has been formalized in the economic literature in different contexts. In the Industrial Organization literature see, for instance, Salop (1977) and Dixit and Stiglitz (1977); in the endogenous growth literature see, for instance, Romer (1990), Aghion and Howitt (1992) and Grossman and Helpman (1991).

${ }^{3}$ Granstrand and Sjölander (1990) present evidence from Sweden and Hall (1990) presents evidence from the US of firms acquiring innovative targets to gain access to their technologies. Bloningen and Taylor (2000) find evidence from US high-tech industries of firms making a strategic choice between the acquisition of outside innovators and in-house R\&D. In the biotech industry, Lerner and Merges (1998) note that acquisitions are important for know-how transfers. OECD (2000, 2002) argues that established firms often acquire firms to get access to new technologies.

${ }^{4}$ See Aghion et al. (2005) for an overview of theories of intensity of competition and innovation. Note that if firms are asymmetric, the most efficient firms' profits might increase when product market competition increases. See, for instance, Boone (2001, 2007) for examples of competition-oligopoly models with such properties. 
we establish that in the case where the entrepreneur will commercialize the invention herself, the classical Schumpetrian argument is indeed valid, i.e. increased competition reduces the incentives for innovations. The reason is that the entrant's product market profit decreases when competition is strengthened and thereby, the rents of innovations are reduced. However, we show that increased product market competition can increase as well as decrease the incentive to innovate in the case when innovations are for sale. The reason is that the incentive to innovate then depends on the acquisition price of the invention. In equilibrium, the acquisition price of the invention is a non-acquiring incumbent's willingness to pay, which consists of two profit terms: the expected product market profit for this firm if it were instead to obtain the invention, and the corresponding profit when not buying. It then follows that the first profit term decreases when competition increases. However, the second profit term will also decrease, which implies that the willingness to pay can increase as well as decrease when competition increases, depending on which is the dominating effect. Consequently, the fear that increased intensity of product market competition risks harming the incentive to innovate seems less motivated when taking into account that entrepreneurs can sell their innovations.

The venture capital industry provides some insightful anecdotal evidence of the relation between innovation for sale and innovation for entry and competition. Figure 1.1 depicts the quarterly value of exits through M\&As and IPOs, respectively, in the US in the stage 1999 to 2005. Note that M\&As dominate as the exit mode, except at the beginning of the stage. According to The Economist $(1999)^{5}$, the exit strategy of venture capital firms changed from initial public offerings (IPOs) to exit by sale in the late 1990's: "Over the past year or so, however, venture-capital firms' exit strategy has changed. ... more and more entrepreneurs are starting enterprises with the express purpose of being bought out in due course." Moreover, according to The Economist (1999), innovators know that incumbent firms that risk tough competition from not buying are willing to pay a great deal for innovations. ${ }^{6}$

Next, we investigate the effects of a strict merger policy which aims at stimulating competition by not allowing mergers leading to markets with too high concentration. ${ }^{7}$ Merger law in most developed countries blocks mergers that increase the concentration levels too much at already high levels. ${ }^{8}$ To this end, we assume that the government initially sets the merger policy by committing to a minimum number of firms allowed in the product market and that the merger market forces will then create a market structure with that number of firms. Then, we show that the incentive for innovation for sale relative to innovation for entry will increase under a stricter merger policy, due to the mechanism described above. A stricter merger policy increases the equilibrium number of firms in the market, which decreases both the entrant's and the acquiring incumbent's profit in a similar fashion. But also the profit of the non-acquiring incumbents decreases which implies that the sales price decreases less than the entrant's profit.

\footnotetext{
5 "Easy way out", The Economist, Feb 181999.

${ }^{6}$ An example is Cerent, which was acquired by Cisco at $\$ 6.9$ billion.

${ }^{7}$ See Motta (2004) and Katz and Shelanski (2005) for a description of merger policy in the EU and the US, respectively.

8 See Katz and Shelanski (2005) for the US and Motta (2004) for the EU. In evaluating horizontal mergers, the US Agency considers both the post-merger market concentration and the increase in concentration resulting from the merger (See http://www.usdoj.gov/atr/public/guidelines/hmg.htm).
} 


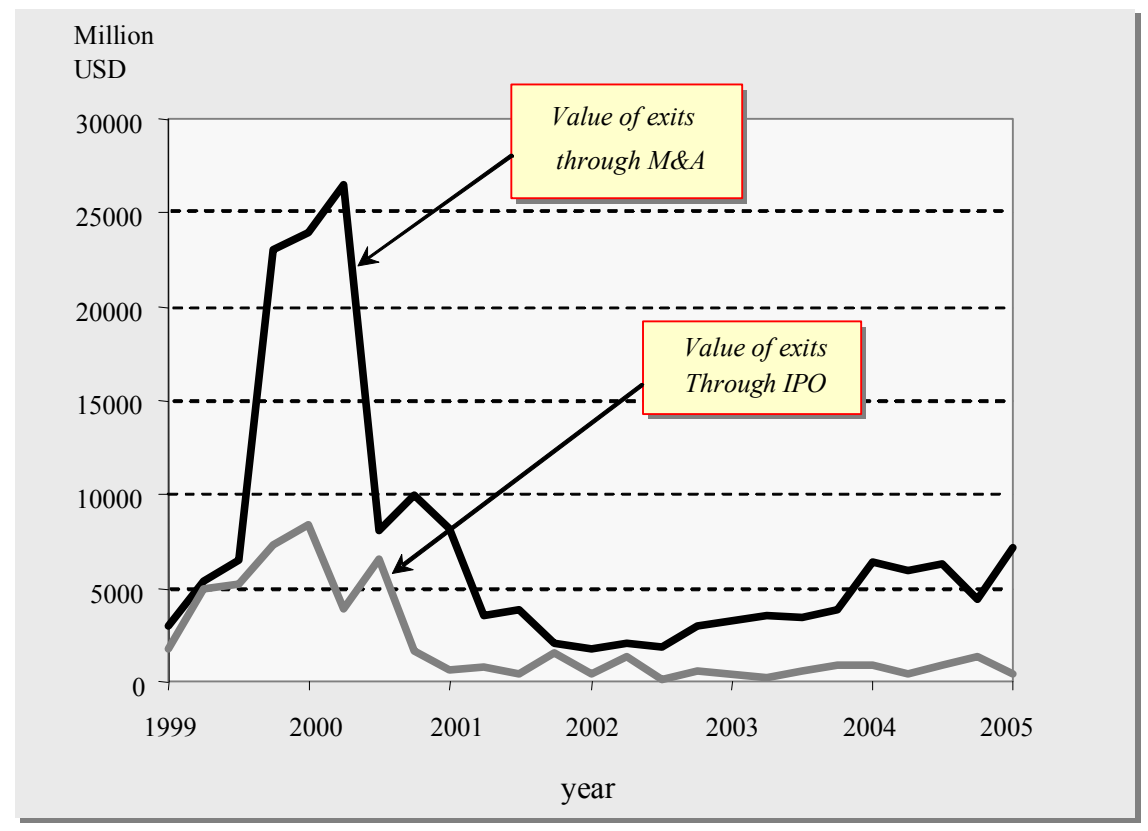

Figure 1.1: The value of exits through M\&A and IPO in the US. Source: Thomson Venture Economics/National Venture Capital Association.

Moreover, we show that a strict, but not too strict, merger policy increases the incentive for innovations for sale. Increasing the equilibrium number of firms in very concentrated markets increases the incentive for innovation for sale, since the bidding competition over the innovation then increases, whereas increasing the number of firms in less concentrated markets leads to a reduced incentive for innovation for sale. The reason is that the fall in the product market price will hurt the larger acquiring firm more, thereby reducing the sales price of the innovation. Hence, we have established an inversely U-shaped incentive for innovation for sale of a stricter merger policy.

We make three contributions to the large literature on innovation and competition. ${ }^{9}$

First, we contribute by examining how the intensity of product market competition affects the pattern of innovation for sale and innovation for entry allowing for bidding competition over the invention. The existing literature shows that the incentive for innovation for sale (incumbent preemptive innovation) decreases if the intensity of product market competition increases (Gilbert and Newbery $(1982,1992)$ and Vickers (1985)). The reason is that the entry profit decreases less than the entry deterring value in intensity of product market competition. However, this literature views the sale of the invention as an isolated bargaining between the entrant and one incumbent. Our contribution here is to allow all incumbents to participate in the bidding competition. We then show that increased intensity of product market competition increases the incentive for innovation for sale relative to the incentive for innovation for entry. The reason for this is that increased intensity of product market competition increases the bidding competition among incumbents over the invention and thereby increases the reward for innovation for sale.

\footnotetext{
${ }^{9}$ For overviews of the literature on innovation and competition see, for instance, Aghion et al. (2005), Motta (2004) and Gilbert (2006).
} 
Second, we add to the existing literature by examining how the intensity of product market competition affects the incentive to innovate by also considering innovation for sale. The previous literature on outsider innovation and competition shows that the incentive for innovation increases if and only if there is an increase in the entrant's profit.(Aghion and Howitt (1992), Dixit and Stiglitz (1977), Grossman and Helpman (1991) and Salop (1977). ${ }^{10}$ The literature on incumbent innovation and competition shows that increased intensity of competition increases the incentive for innovation if and only if the difference between a firm's profits in the market with the invention and the profit it makes in the market absent the invention increases (the "escape-competition effect" identified in Aghion et al. (2005) and present in Vives (2008), and related to the Arrow (1962) classical replacement effect). We contribute by showing that increased intensity of competition increases the incentive for innovation for sale if and only if the difference between the with-innovation rents and the without-innovation rents in the market with the invention increases. This implies that the profits in the pre-innovation market do not affect the incentive to innovate for sale.

Third, we contribute to the literature by examining how competition policy affects the incentive for innovation for sale. In the previous literature, competition policy has been shown to play an important role for the innovation incentive by once more affecting the relation between the profit in the market with the invention and the profit in the market absent the invention (Aghion et al. 2005) and by affecting the time flow of rents (Segal and Whinston 2007). Here, we identify another important role of competition (merger) policy for the incentive for innovation through its effect on the intensity of competition over innovations for sale, thereby increasing the incentive to innovate for sale.

The paper also adds to the literature on the pattern of commercialization for entry and sale (licence) which shows that commercialization by sale (licence) is more likely when entry costs are high, the entrepreneurial firm lacks complementary assets, brokers facilitating trade are available, and the expropriation problem associated with asset transfers is low. ${ }^{11}$ Our contribution is here to show that when the innovation will be commercialized in an oligopolistic market, it is more likely that the innovation is commercialized through the sale to an incumbent when the intensity of product market competition increases.

This paper also relates to the literature on auctions with externalities (see, for instance, Jehiel, Moldovanu and Stacchetti $(1996,1999))$ which has shown that the externalities associated

\footnotetext{
${ }^{10}$ Boone (2001) also studies how the intensity of competition affects innovation for sale. In fact, our definition of intensity of competition is inspired by Boone (2001) which uses four conditions on how profits are affected by intensity of competition. However, his third condition states that if the leader is sufficiently far ahead, he gains as competition becomes more intense, i.e. $\frac{d \pi_{l}}{d C}>0$ for the leader. This is not a necessary condition in our set-up for the result that increased intensity of competition increases the incentive for innovation for sale.

Moreover, Boone uses a specific set-up where the innovator cannot enter but can make a take-or-leave-it offer to the incumbents. Instead, we use the auction with an externality set-up (see, for instance, Jehiel, Moldovanu, and Stacchetti (1999) and Jehiel and Moldovanu (2000)). This enables us to more generally solve for the equilibrium ownership (EOS) of the invention and undertake illustrative comparative statics (intensity of product market competition, bidding competition and synergies) on the EOS.

${ }^{11}$ See, for instance, Anton and Yao (1994), Chan, Nickerson and Owan (2009), Gans and Stern (2000, 2003), Gans et al. (2002), Hall and Ziedonis (2001) and Teece (1987).
} 
with the use of an object for sale will affect the equilibrium identity of the buyer, the sales price, and that traditional auction formats need then not be efficient. We add to this literature by endogenizing the effort to undertake $R \& D$ to provide inventions with externalities for sale in an environment where the potential seller can choose to sell the asset or use it to compete with the potential buyers, and by examine how this incentives depend on the intensity of competition in the market. ${ }^{12}$

This paper can also be seen as a contribution to the literature on entrepreneurship and innovations. ${ }^{13}$ We extend this literature by allowing for the interaction between entrepreneurs and oligopolist in the innovation process and study how the intensity of competition and competition policy affects the incentive for entrepreneurial innovations. ${ }^{14}$

In Section 2, an illustrative example of the main mechanism of the paper is presented. The model is spelled out in Section 3. Section 4 studies the effects of increased intensity of competition on the pattern of entry and sale and the incentive to innovate. In Section 5, we study how merger policy affects the pattern of entry and sale and the incentive to innovate. In Section 6 , we explore how our results are affected by allowing the entrepreneur to sell licences of a patent of its innovation, allowing for synergies, and allowing for asymmetric firms. Section 7 concludes the paper.

\section{A simple example}

We here illustrate the main mechanisms of the paper in a very simple setting before turning to the main model. This a simplified version of the Cournot model with differentiated products (CDP model) presented in detail in Section 4 below. Consider a three-stage game where a product market is initially served by two symmetric incumbents, $i_{1}$ and $i_{2}$. There is also an entrepreneur, denoted $e$, which undertakes an effort to create an invention denoted with a given quality $\bar{k}$.

The final stage 3 is a Cournot model with differentiated products, where incumbents (or the incumbents and the entrepreneur) face inverse demand

$$
P_{j}\left(q_{j}, q_{-j}\right)=a-q_{j}-\gamma q_{-j},
$$

where $\gamma \in(0,1]$ is the (inverse) level of product differentiation (a larger $\gamma$ gives more homogenous products). ${ }^{15}$ Note that $\gamma$ gives a natural measure of product market competition. Let $\pi_{j}=$ $\left[P_{j}-c_{j}\right] q_{j}$ be the direct profit function where $c_{j}=c$ when firm $j$ does not possess the invention

\footnotetext{
${ }^{12}$ Most papers in this literature treat the size of the asset for sale as exogenous. To our knowledge, the only exception are Katz and Shapiro (1986) who determine the optimal licensing fee of a research lab which can affect the size of the innovation and Norbäck and Persson (2009) who determine the optimal development investment for an venture-backed firm that will exit bu a trade sale to an incumbent.

See Segal (1999) for a paper on contracting with externalities.

${ }^{13}$ For overviews, see Acs and Audretsch (2005) and Bianchi and Henrekson (2005).

14 Baumol (2004) stresses the importance of the different roles played by small entrepreneurial firms and large established firms in the innovation process in the US, where small entrepreneurial firms create a large share of breakthrough innovations and where large established firms provide more routinized R\&D.

${ }^{15}$ For ease of presentation, we omit the monopoly case of $\gamma=0$.
} 
and $c_{j}=c-\bar{k}$ is the marginal cost when firm $j$ possesses the invention. From the Nash-quantities in the product market interaction $\mathbf{q}^{*}(l)=\left(q_{j}^{*}(l), q_{-j}^{*}(l)\right)$, let $\pi_{j}(l)=\left[P_{j}\left(\mathbf{q}^{*}(l)\right)-c_{j}\right] q_{j}^{*}(l)$ be the reduced-form profit of firm $j$, where $l$ indicates which firm owns the innovation $k$. In stage 2 , the entrepreneur decides whether to enter the market or sell the invention to one of the incumbents (i.e. $l$ is determined). The market structures can then be Duopoly (D) or Triopoly (T). In stage 1, the entrepreneur expands the effort to innovate (to increase the probability of inventing an innovation with quality $\bar{k}$ ).

The typical concern in the literature is that the product market profits of all firm types decrease in the level of intensity of product market competition, i.e. $\frac{d \pi_{j}(l)}{d \gamma}<0$, and thereby the incentive for innovation is reduced. Let us focus on this case. It can then be shown that there is a region $\gamma \in(0, \tilde{\gamma}]$ where $\frac{d \pi_{j}(l)}{d \gamma}<0$ is fulfilled. ${ }^{16}$

In stage 2 , there is an entry-acquisition auction where incumbents simultaneously post bids and the entrepreneur then either accepts or rejects these bids; if it rejects the bids, the entrepreneur will enter the market if and only if the product market profit covers the entry cost $F$. There are three different valuations which need to be considered:

- $v_{e}$ is the entry value (or reservation price), i.e. the profit for the entrepreneur when competing with both incumbents $\left(\pi_{E}^{T}(e)-F\right)$ :

$$
v_{e}=\pi_{E}^{T}(e)-F
$$

- $v_{i e}$ is the entry-deterring valuation, i.e. an incumbent's profit of possessing the invention, $\pi_{A}^{D}(i)$, minus its profit if the entrepreneur would otherwise enter, $\pi_{N}^{T}(e)$ :

$$
v_{i e}=\pi_{A}^{D}(i)-\pi_{N}^{T}(e)
$$

- $v_{i i}$ is the preemptive valuation, i.e. an incumbent's profit of possessing the invention $\pi_{A}^{D}(i)$ ) minus its profit if the rival would otherwise obtain the invention, $\left.\pi_{N}^{D}(i)\right)$ :

$$
v_{i i}=\pi_{A}^{D}(i)-\pi_{N}^{D}(i)
$$

Figure 2.1 (i) shows the different valuations of the invention for the different owners, and how these valuations depend on the intensity of product market competition measured through the level of product differentiation $\gamma$. Figure 2.1 (ii) summarizes the Equilibrium Ownership Structure (EOS). Figure 2.1 (iii) summarizes the reward to the entrepreneur $R_{E}$ as a function of the intensity of product market competition.

To highlight our main mechanism, we assume that the entry cost $F$ is at a level such that $v_{e}>v_{i e}$ at $\gamma$ close to zero. Thus, at a low intensity of product market competition, the entrepreneur has a stronger incentive to commercialize through entry than through sale. What then occurs if intensity of competition increases? As illustrated in Figure 2.1 (i), (2.2) implies

\footnotetext{
${ }^{16}$ See Lemma 4, below.
} 
that increased product market competition decreases the entry value $v_{e}$ :

$$
\frac{d v_{e}}{d \gamma}=\frac{d \pi_{E}^{T}(e)}{d \gamma}<0
$$

Now turn to incumbents' valuations. Note that without synergies between the invention and incumbents' assets, it immediately follows that $v_{i e}-v_{i i}=\pi_{N}^{D}(i)-\pi_{N}^{T}(e)>0$. Then, differentiating $v_{i e}-v_{e}$, it can be shown that ${ }^{17}$

$$
\begin{aligned}
& \frac{d v_{i e}}{d \gamma}-\frac{d v_{e}}{d \gamma}=\frac{d \pi_{A}^{D}(i)}{d \gamma}-\frac{d \pi_{E}^{T}(e)}{d \gamma}-\frac{d \pi_{N}^{T}(e)}{d \gamma}>0 . \\
& \underbrace{(-) \quad(-)}_{\text {Small in absolute value }}
\end{aligned}
$$

Thus, the entry-deterring valuation of an incumbent $v_{i e}$ increases (decreases less than the entrepreneur's value of entry $v_{e}$ ) when the intensity of product market competition increases. The reason for this is that a higher intensity of product market competition decreases entrants' and acquirers' profits in a similar fashion $\left(\frac{d \pi_{A}^{D}(i)}{d \gamma}-\frac{d \pi_{E}^{T}(e)}{d \gamma}\right.$ is small in absolute value). However, since the profit of a non-acquirer $\pi_{N}^{T}(e)$ decreases in $\gamma$, this creates an additional increase in the incumbent valuation, thereby implying that $\frac{d v_{i e}}{d \gamma}>\frac{d v_{e}}{d \gamma}$. In fact, as shown in Figure 2.1 (i), the negative effect on the non-acquirer $\frac{d \pi_{N}^{T}(e)}{d \gamma}<0$ can be so large that the entry-deterring valuation is increasing, $\frac{d v_{i e}}{d \gamma}=\frac{d \pi_{A}^{D}(i)}{d \gamma}-\frac{d \pi_{N}^{T}(e)}{d \gamma}>0$.

Thus, at increased product market competition, a sale of the innovation becomes more likely since $\frac{d v_{i e}}{d \gamma}>\frac{d v_{e}}{d \gamma}$ from (2.6). At $\gamma=\gamma^{E D}, v_{i e}=v_{e}$ holds and further increases in intensity of product market competition $\gamma$ will make an entry deterring acquisition strictly profitable as $v_{i e}>v_{e}$. As shown in Figure 2.1(ii), an acquisition of the invention then takes place at price $S^{*}=v_{e}=\pi_{E}^{T}(e)-F$. This is illustrated at point ED in Figure 2.1(i).

A further increase in product market competition $\gamma$ will lead to incumbents' preemptive valuations $v_{i i}$ exceeding the entry value of the entrepreneur $v_{e}:^{18}$

$$
\begin{aligned}
& \frac{d v_{i i}}{d \gamma}-\frac{d v_{e}}{d \gamma}=\frac{d \pi_{A}^{D}(i)}{d \gamma}-\frac{d \pi_{E}^{T}(e)}{d \gamma}-\frac{d \pi_{N}^{D}(i)}{d \gamma}>0 . \\
& \underbrace{(-)}_{\text {Small in absolute value }}
\end{aligned}
$$

As shown in Figure 2.1(i), at $\gamma=\gamma^{P E}, v_{i i}=v_{e}$ holds. This induces a bidding war among incumbents which drives the equilibrium sales price above the entry value for the entrepreneur, i.e. $S^{*}=v_{i i}$.

Using Figure 2.1(i) and (ii), we can then state our first result:

Result 1 Suppose that the intensity of product market competition increases. The acquiring incumbent's willingness to pay is less negatively affected than the entrepreneur's reservation price, since increased intensity of product market competition also makes it less favorable to become a non-acquirer. Thus, higher intensity of product market competition can lead to commercialization by sale to an incumbent.

\footnotetext{
${ }^{17}$ See the Appendix.

${ }^{18}$ See the Appendix for proofs.
} 


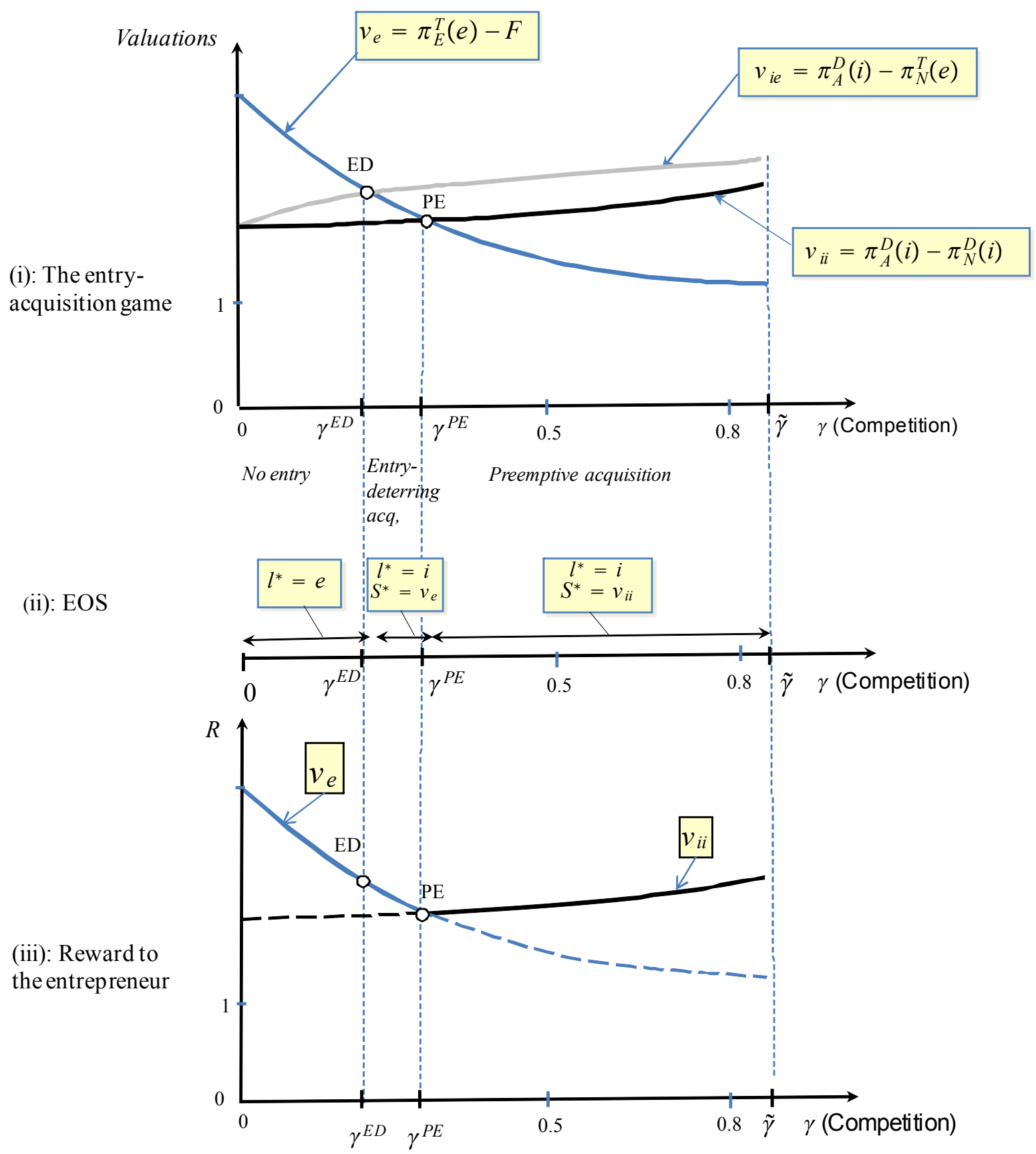

Figure 2.1: Why stronger competition leads to more commercialization by sale and increased innovation incentives for entrepreneurs. Parameter values at: $\Lambda=a-c=3, k=1$. 
In stage 1, the entrepreneur decides how much to invest in research, depending on the reward for taking an invention to the market. Inspecting Figure 2.1(ii), we see that the reward to the entrepreneur becomes:

$$
R_{E}(l)=\left\{\begin{array}{c}
v_{e}, \quad \gamma \in\left[0, \gamma^{E D}\right), \\
S^{*}=v_{e}, \quad \gamma \in\left[\gamma^{E D}, \gamma^{P E}\right), \\
S^{*}=v_{i i}, \gamma \in\left[\gamma^{P E}, \tilde{\gamma}\right] .
\end{array}\right.
$$

We can then immediately state the following result:

Result 2 Suppose that the intensity of product market competition increases. The reward for innovation for sale can then increase (even though the incentive for innovation for entry decreases). The reason is that increased intensity of product market competition increases the bidding competition over the invention.

Finally, let us add a stage 0 where a merger between the two incumbents $i_{1}$ and $i_{2}$ is proposed to the competition authority which may then block this merger. It then follows that the entrepreneur's incentive to innovate may be substantially smaller after a merger. To see this, note that the entrepreneur obtains $R_{E}=v_{i i}=\pi_{A}^{D}(i)-\pi_{N}^{D}(i)$ under high intensity of product market competition $\left(\gamma>\gamma^{P E}\right)$ absent the merger since the incumbents compete to acquire the invention. When the merger is allowed, the single incumbent will only offer the entrepreneur her reservation price and thus the reward becomes $R_{E}^{\mathrm{Merger}}=v_{e}=\pi_{E}^{D}(e)-F$. Since $\pi_{A}^{D}(i)=\pi_{E}^{D}(e)$, it follows that the reward for the entrepreneur absent a merger $\left(R_{E}\right)$ is higher than the reward with a merger $\left(R_{E}^{\text {Merger }}\right)$ iff $F>\pi_{N}^{D}(i)$. The latter condition is more likely to hold, the stronger is the product market competition $\gamma\left(\right.$ since $\left.\frac{d \pi_{N}^{D}(i)}{d \gamma}<0\right)$.

Thus, we can state the following result:

Result 3 Suppose that the intensity of product market competition is strong. Merger policy can then increase the reward to innovation by sustaining the bidding competition over the invention.

In a very simple setting, we have shown several new aspects of product market competition. Strong product market competition induces entrepreneurs to sell new inventions to incumbent firms; strong product market competition can increase innovation incentives under commercialization by sale; merger policy is important for the reward to innovation by sustaining bidding competition. We will now turn to the main model where we show under which conditions these three results hold in a more general setting.

\section{The Model}

Consider a market served by $n$ symmetric incumbent firms. There is also an entrepreneur, denoted $e$, investing in an innovative activity that could lead to the creation of a unique productive asset, denoted $\bar{k}$. The interaction is illustrated in Figure 3.1. In stage 1, the intensity of competition $C$ is determined by nature (or government policy as in section 5 ). In stage 2 , the entrepreneur decides how much to invest in research, thereby affecting the probability of 


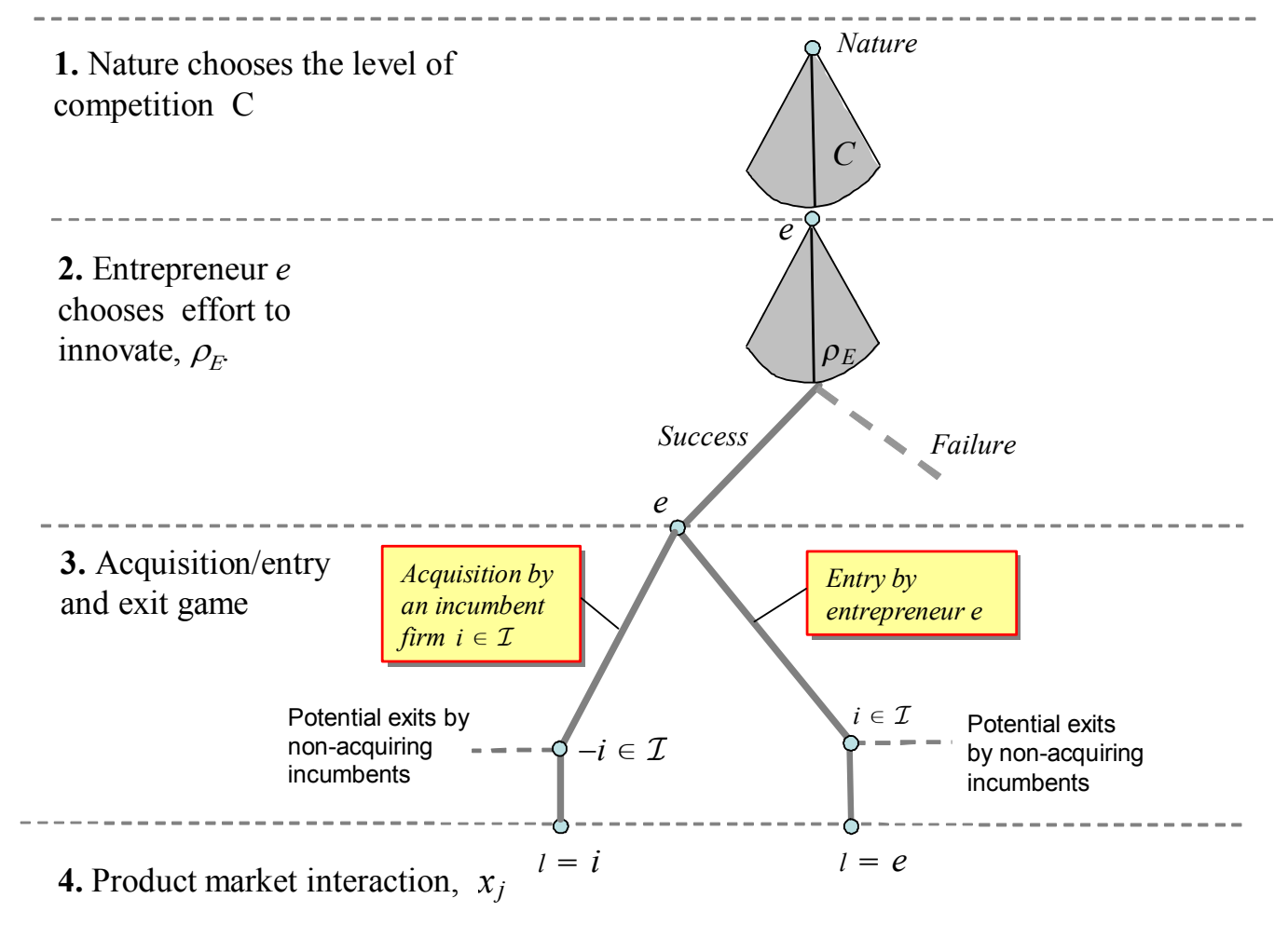

Figure 3.1: The sequence of the game.

discovering $\bar{k}$. In stage 3 , given successful innovation, one of the incumbent firms acquires the entrepreneur's assets $\bar{k}$, or the entrepreneur enters the market. Depending on the level of the intensity of competition, there may be exits of non-acquiring incumbents. Finally, in stage 4, firms compete in oligopoly fashion.

\subsection{Stage 4: product market interaction}

Let the set of firms in the industry be $\mathcal{J}=e \times \mathcal{I}$, where $\mathcal{I}=\left\{i_{1}, i_{2} \ldots i_{m}\right\}$ is the set of incumbent firms. There are $m$ incumbent firms. Let the set of potential ownerships of the entrepreneur's innovation, $\bar{k}$, be $L=\left\{e, i_{1}, i_{2} \ldots i_{m}\right\}$.

$\pi_{j}(x, l: \bar{k}, C)$ denotes the variable product market profit of firm $j$, where $\mathbf{x}=\left(x_{e}, x_{i_{1}, \ldots} x_{i_{n}}\right)$ is the vector of actions taken by firms in product market interaction, $l$ keeps track of the identity of the firm owning the innovation, $\bar{k}$ denotes the quality of the innovation and $C$ denotes the intensity of product market competition. We are now set to describe the optimal behavior in product market interaction. Firm $j$ chooses an action $x_{j} \in R^{+}$to maximize its product market profit, denoted $\pi_{j}\left(x_{j}, x_{-j}: l\right)-f$, where $x_{-j}$ is the set of actions taken by $j$ 's rivals where we have omitted $\bar{k}$ and $C$ as arguments. Firms pay a fixed cost $f$ to serve the market. The action $x_{j}$ may be considered as setting a quantity or a price, as will be shown in later sections. We assume there to exist a unique Nash-Equilibrium, $x^{*}(l)$, defined as:

$$
\pi_{j}\left(x_{j}^{*}, x_{-j}^{*}: l\right) \geq \pi_{j}\left(x_{j}, x_{-j}^{*}: l\right)
$$


where we assume the product market profits to be positive.

From (3.1), we can define a reduced-form product market profit for a firm $j$, taking as given ownership $l$, since:

$$
\pi_{j}(l) \equiv \pi_{j}\left(x_{j}^{*}(l), x_{-j}^{*}(l), l\right) .
$$

The assumption that incumbents $i_{1}, i_{2}, \ldots, i_{n}$ are symmetric before the acquisition takes place implies that we need only distinguish between two types of ownership; entrepreneurial ownership $(l=e)$ and incumbent ownership $(l=i)$. Note that there are three types of firms of which to keep track, $h=\{e, A, N\}$, i.e. the entrepreneurial firm $(e)$, an acquiring incumbent $(A)$ and non-acquiring incumbents $(N)$.

Given that a sale of the innovation $\bar{k}$ occurs, $\pi_{A}(i)$ denotes the acquiring firm's reduced-form product market profit and $\pi_{N}(i)$ the corresponding profit for a non-acquirer. If no sale occurs and the entrepreneur enters the market, $\pi_{e}(e)$ denotes the entrepreneurial firm's reduced-form product market profit and $\pi_{N}(e)$ the corresponding profit for an incumbent.

Let us finally define the quality of the innovation $\bar{k}$ and the intensity of competition $C$ in the model. Typically, the value of innovations in the market will differ substantially. To capture this aspect, we define the quality of an innovation as follows:

Definition 1. Quality of the innovation: when the quality of the innovation increases, the profit of the possessor increases and the profit of the rivals decreases, i.e. $\frac{d \pi_{A}(i)}{d k}>0$, $\frac{d \pi_{E}(e)}{d k}>0$, and $\frac{d \pi_{N}(l)}{d k}<0, l=e, i$.

Definition 1 is valid in the Differentiated Product Cournot (CDP) model which is presented in more detail below, but it is also compatible with other oligopoly models (e.g. Farrell and Shapiro (1996)), where increased quality is interpreted as increased size of capital holdings. ${ }^{19}$

The intensity of product market competition $C$ is not a well defined concept and many different kinds of formalizations have been used in the literature. However, in many formalizations, product market profits will be reduced when the intensity of product market competition is increased. ${ }^{20}$ We then make the following definition of competition:

Definition 2. Intensity of product market competition: when the intensity of product market competition increases, there is a decrease in the product market profits for all firm types $h$ active in the product market, i.e. $\frac{d \pi_{h}(l)}{d C}<0, l=e, i$.

For instance, it is shown in the Appendix that the definition is valid for a large parameter set in the CDP model, where we model increased competition as increased substitutability between products or as an increase in the number of firms. The Appendix shows that the results also extend into Bertrand competition. Moreover, it can be shown that the definition is also valid in a Shubik-Levitan type of differentiated product model and in a Salop type of circular model of horizontal product differentiation.

\footnotetext{
${ }^{19}$ Note that the definition may not hold if there are strong technological spillovers between firms.

20 See Aghion et al. (2005) for overviews of theories of intensity of competition and innovation, and Boone (2007) for a measure of competition based on the relative profits of efficient and inefficient firms.
} 


\subsection{Stage 3: the acquisition-entry-exit game}

In stage 3 , there is a first period with an entry-acquisition game where the entrepreneur can decide whether to sell the innovation to one of the incumbents or enter the market. Given the mode of commercialization of the innovation, there is a second period, with an exit game, where non-acquiring incumbents might exit. The possessor of the innovation is assumed to always make positive profits, i.e. $\pi_{h}(l)>f, h=A, E$.

Formally, exits of non-acquiring incumbents will occur until the total number of firms on the market $n(l)$ fulfils the exit condition:

$$
\pi_{N}(l: n(l))>f, \quad \pi_{N}(l: n(l)+1)<f .
$$

The acquisition-entry process is depicted as an auction where $m$ incumbents simultaneously post bids and the entrepreneur then either accepts or rejects these bids; if it rejects the bids, the entrepreneur will enter the market if and only if it is profitable. Each incumbent announces a bid, $b_{i}$, for the invention. $b=\left(b_{1}, . . b_{i} . ., b_{m}\right) \in R^{m}$ is the vector of these bids. Following the announcement of $b$, the invention may be sold to one of the incumbents at the bid price, or remain in the ownership of the entrepreneur, $e$. If more than one bid is accepted, the bidder with the highest bid obtains the invention. If there is more than one incumbent with such a bid, each such incumbent obtains the invention with equal probability. The acquisition is solved for Nash equilibria in undominated pure strategies. There is a smallest amount, $\varepsilon$, chosen such that all inequalities are preserved if $\varepsilon$ is added or subtracted.

There are three different valuations which need to be considered:

- $v_{i i}$ is the value for an incumbent of obtaining $\bar{k}$, when a rival incumbent would otherwise obtain $\bar{k}$

$$
v_{i i}=\pi_{A}(i)-f-\lambda(\mathrm{i})\left[\pi_{N}(i)-f\right] .
$$

The first term shows the profit when possessing the innovation, $\bar{k}$. The second term shows the expected profit if a rival incumbent obtains $\bar{k}$, where $\lambda(i)=\frac{n(i)-1}{m-1}$ is the probability of remaining in the market as a non-acquirer under a sale of the innovation since $m-1$ is the maximum number of non-acquiring incumbents under a sale and $n(i)-1$ is the number of non-acquiring incumbents remaining on the market given from (3.3).

- $v_{i e}$ is the value for an incumbent of obtaining $\bar{k}$, when the entrepreneur would otherwise keep them

$$
v_{i e}=\pi_{A}(i)-f-\lambda(\mathrm{e})\left[\pi_{N}(e)-f\right] .
$$

The profit for an incumbent of not obtaining invention $\bar{k}$ is different in this case, due to the change of identity of the firm which would otherwise possess the assets $\bar{k}$, where $\lambda(e)=\frac{n(e)-1}{m}$ is the probability of remaining in the market as a non-acquirer when entry occurs, $m$ is the maximum number of non-acquiring incumbents when entry occurs and $n(e)-1$ is the number of non-acquiring incumbents remaining in the market, given from (3.3). 
- $v_{e}$ is the value for the entrepreneur of keeping $\bar{k}$.

$$
v_{e}=\pi_{E}(e)-f-F
$$

where the entrepreneur has the entry cost $F$. Note also that we assume that $\pi_{E}(i)=0$, so that the entrepreneur cannot enter the market without ownership of the innovation. An alternative interpretation is that $v_{e}$ is the value for an outside firm, i.e. a firm without initial assets in the industry, of acquiring the entrepreneur's innovation.

We can now proceed to solve for the Equilibrium Ownership Structure (EOS). Since incumbents are symmetric, valuations $v_{i i}, v_{i e}$ and $v_{e}$ can be ordered in six different ways, as shown in table 3.1. These inequalities are useful for solving the model and illustrating the results. We can state the following lemma:

Lemma 1. The equilibrium ownership structure and the acquisition price are described in table 3.1:

Proof. See the Appendix.

Table 3.1: Equilibrium ownership structure and acquisition price.

\begin{tabular}{ccccc}
\hline Inequality: & Definition: & Ownership $l^{*}:$ & Acquisition price, $S^{*}:$ & Entrepreneurial reward, $R_{E}:$ \\
\hline$I 1:$ & $v_{i i}>v_{i e}>v_{e}$ & $i$ & $v_{i i}$ & $v_{i i}$ \\
$I 2:$ & $v_{i i}>v_{e}>v_{i e}$ & $i$ or $e$ & $v_{i i}$ & $v_{i i}$ or $v_{e}$ \\
$I 3:$ & $v_{i e}>v_{i i}>v_{e}$ & $i$ & $v_{i i}$ & $v_{i i}$ \\
$I 4:$ & $v_{i e}>v_{e}>v_{i i}$ & $i$ & $v_{e}$ & $v_{e}$ \\
$I 5:$ & $v_{e}>v_{i i}>v_{i e}$ & $e$ &. & $v_{e}$ \\
$I 6:$ & $v_{e}>v_{i e}>v_{i i}$ & $e$ &. & $v_{e}$ \\
\hline
\end{tabular}

Lemma 1 shows that when one of the inequalities $I 1, I 3$, or $I 4$ holds, $\bar{k}$ is obtained by one of the incumbents. Under $I 1$ and $I 3$, the acquiring incumbent pays the acquisition price $S=v_{i i}$, and $S=v_{e}$ under $I 4$. When $I_{5}$ or $I_{6}$ holds, the entrepreneur keeps its assets. When $I 2$ holds, there exist multiple equilibria.

\subsection{Stage 2: innovation activity}

In stage 2 , entrepreneur $e$ undertakes an effort $\rho_{E}$ to discover an innovation. Assume that the probability of succeeding with an innovation is simply the effort, i.e. $\rho_{E} \in[0,1]$, and that $\rho_{E}$ can be privately chosen by the entrepreneur at an increasing and convex cost $y(\rho)$, i.e. $y^{\prime}(\rho)>0$, and $y^{\prime \prime}(\rho)>0 . \Pi_{E}=\rho_{E} R_{E}(l)-y\left(\rho_{E}\right)$ is then the expected net profit for the entrepreneur, 
where $R_{E}(l)$ is the reward for a successful innovation given from table 3.1:21

$$
R_{E}(l)=\left\{\begin{array}{c}
v_{e}, \mathrm{I} 5 \text { or } \mathrm{I} 6 \text { and } l=e \\
v_{e}, \quad \mathrm{I} 4 \text { and } l=i \\
v_{i i}, \mathrm{I} 1, \mathrm{I} 2 \text { or } \mathrm{I} 3 \text { and } l=i
\end{array} .\right.
$$

The entrepreneur then maximizes $\Pi_{E}$, optimally choosing effort $\rho_{E}$. The optimal effort $\rho_{E}^{*}$ is given from:

$$
\frac{d \Pi_{E}}{d \rho_{E}}=R_{E}(l)-y^{\prime}\left(\rho_{E}^{*}(l)\right)=0,
$$

with the associated second-order condition (omitting the ownership variable $l$ ), $\frac{d^{2} \Pi_{E}}{d \rho_{E}^{2}}=-y^{\prime \prime}(\rho)<$ 0 .

Applying the implicit function theorem in (3.8), we can state the following Lemma:

Lemma 2. The equilibrium effort by the entrepreneur in stage $2, \rho_{E}^{*}(l)$ and hence, the probability of a successful innovation, increases in the reward for an innovation, i.e. $\frac{d \rho_{E}^{*}(l)^{*}}{d R_{E}(l)}>0$.

\section{Intensity of competition, mode of commercialization and the entrepreneur's incentives to innovate}

In this section, we examine how entry and sale patterns and the entrepreneur's incentive to innovate depend on the intensity of product market competition, $C$. In order to isolate the strategic effect of intensity of competition on the entrepreneur's choice between entering and selling the innovation, we assume that the entrant and the acquirer make symmetric use of assets and obtain a symmetric market position when exposed to the same market conditions, i.e. $\pi_{A}(i)=\pi_{E}(e)$ for $n(i)=n(e)$. We refer to such entry as large scale entry and note that one possibility is that large scale entry takes place through a sale to a large firm outside this industry that uses the innovation to enter the market. Then, we note that Lemma 1 implies that a sale takes place if and only if $v_{i l}-v_{e}>0$. To proceed, we will now examine the net value of an incumbent acquisition, i.e. the difference between the incumbents' valuations and the entry value for the entrepreneur, $v_{i l}-v_{e}$. Using (3.4)-(3.6), we have:

$$
v_{i l}-v_{e}=\left[\pi_{A}(i)-\pi_{E}(e)+F\right]-\lambda(1)\left[\pi_{N}(l)-f\right], \quad l=\{e, i\} .
$$

The first term is an innovation-transfer effect and shows the change in profits from an ownership change of the innovation from the entrepreneur to an incumbent firm. The second term can be viewed as the opportunity cost of an ownership change, since this terms captures the profit for an incumbent when not acquiring the innovation.

The fact that the innovation will be used in the market may generate the exit of some of the incumbents. The exit pattern will depend on the quality of the innovation, the level of the intensity of competition, entry mode and the demand and cost structure. In the below analysis, we will make a distinction between three cases: no exit, exit by one firm when entry takes place

\footnotetext{
${ }^{21}$ If $I 2$ in table 3.1 arises, we assume that entry through sale occurs.
} 
and multiple-firm exits. We start with the assumption that one firm exits when entry takes place to illustrate the main mechanism.

Again, we will frequently use the Cournot model with Differentiated Products (CDP Model) to illustrate results. The CDP Model is described in Example 1. A Bertrand model with a Differentiated Products Model (BDP Model) is given in Example 2. A full representation of the exit pattern (no exit, one firm exit, and multiple-firm exit) and equilibrium outcomes in the CDP Model is presented in Figure 4.3.

\subsection{Why increased intensity of competition is conducive to innovation for sale}

To highlight the strategic difference between entering and selling the innovation, we will first examine the case where entry does not affect the long-run equilibrium market structure. Thus, if a sale occurs, there are $m$ active firms in the market, whereas if entry occurs there are still $m$ active firms in the market since one incumbent will exit, i.e. $n(i)=n(e)=m$. We will then study the case where no exit occurs in Section 4.3.1 and where multiple firm exit occurs in Section 4.3.2.

To proceed, we then use the following definition:

Definition 3. $\pi_{N}(l, \bar{C}(l))=f$ for $l=e, i$.

$\bar{C}(l)$ is thus the maximum intensity of competition such that all non-acquirers can cover their fixed cost $f$ associated with serving the market. It follows that $\bar{C}(i)>\bar{C}(e)$ since non-acquirers' profits will be lower with one more firm in the market.

We then make the following assumption:

Assumption A1 Market-structure-neutral-entry: $C \in(\bar{C}(e), \bar{C}(i))$.

Thus, when $C \in(\bar{C}(e), \bar{C}(i))$, entry by the entrepreneur leads to the exit of one incumbent firm. Assumption A1 implies that the entrant obtains exactly the same market position as would the acquiring incumbent in the case of a sale of the innovation, i.e. $\pi_{A}(i)=\pi_{E}(e)$.

Moreover, since one of the incumbents is forced out of the market under entry, we have that the probability of remaining in the market for a non-acquiring incumbent is $\lambda(\mathrm{i})=1>\lambda(\mathrm{e})=$ $\frac{m-1}{m}>0$. Thus, (4.1) can be written as:

$$
v_{i l}-v_{e}=\left\{\begin{array}{c}
v_{i e}-v_{e}=F-\left(\frac{m-1}{m}\right)\left[\pi_{N}(e)-f\right], \quad l=e \\
v_{i i}-v_{e}=F-\left[\pi_{N}(e)-f\right], \quad l=i .
\end{array},\right.
$$

where the innovation-transfer effect is now simply the fixed cost savings, $F . v_{i e}-v_{e}$ then represents the net value for an incumbent of deterring entry, whereas $v_{i i}-v_{e}$ represents the net value for an incumbent of preempting rivals from obtaining the entrepreneur's innovation.

To proceed, we then make use of the following definition:

Definition 4. Let $C^{E D}$ be defined from $v_{i e}\left(C^{E D}, \cdot\right)=v_{e}\left(C^{E D}, \cdot\right)$ and $C^{P E}$ be defined from $v_{i i}\left(C^{P E}, \cdot\right)=v_{e}\left(C^{P E}, \cdot\right)$. 


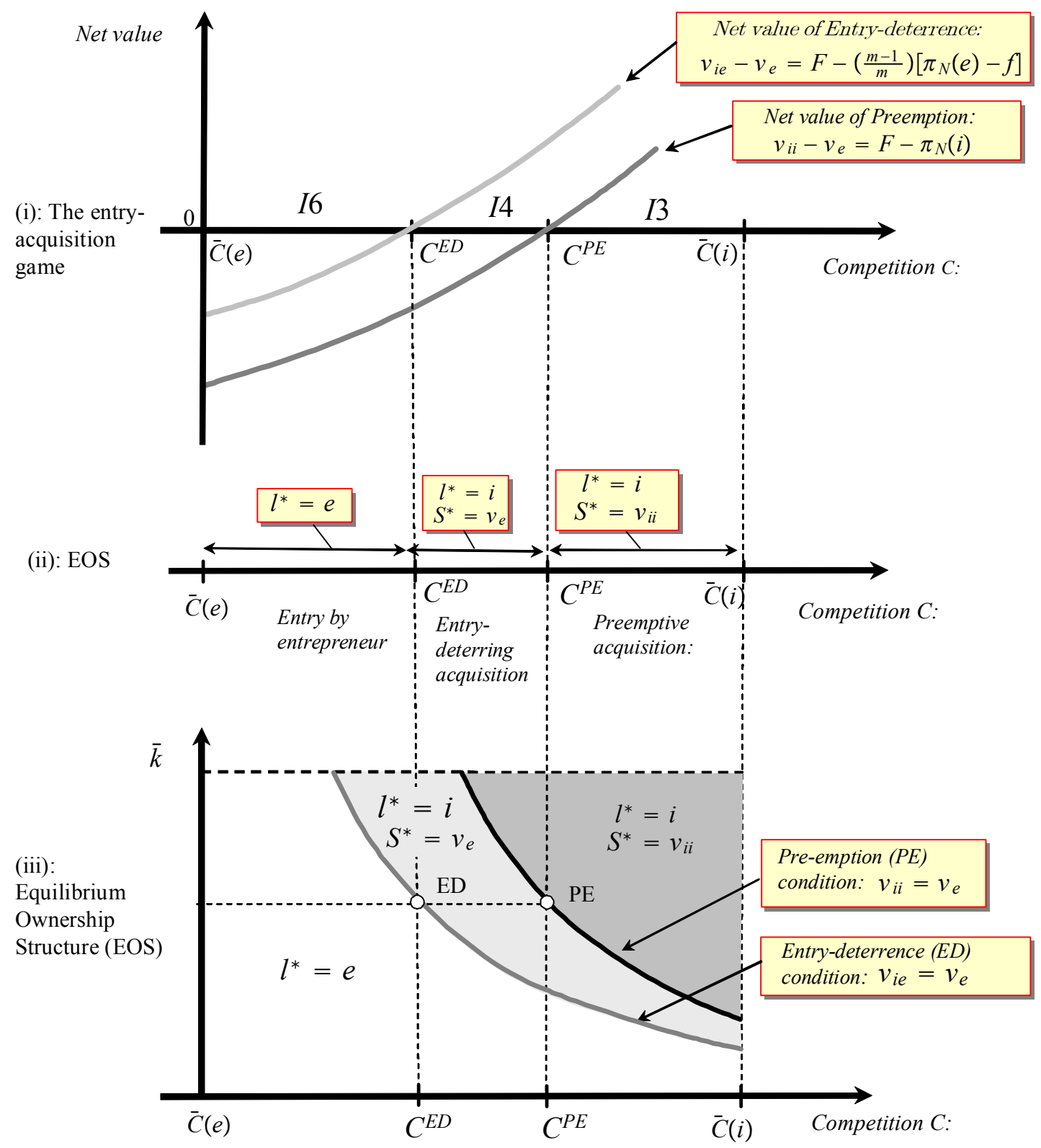

Figure 4.1: Mode of commercialization and intensity of competition. 
$C^{E D}$ is thus the level of competition where the entry-deterring motive for an incumbent acquisition just matches the entrepreneur's entry value, whereas $C^{P E}$ is the level of competition where the preemptive motive for an incumbent acquisition is equal to the entrepreneur's entry value.

We can then state the following proposition:

Proposition 1. Suppose that Assumption $A 1$ holds and $C^{E D}$ and $C^{P E}$ exist. Then, (i) commercialization by entry takes place if competition is sufficiently low, $C \in\left(\bar{C}(e), C^{E D}\right)$, (ii) commercialization by sale occurs at sales price $S^{*}=v_{e}$ if competition is of intermediate size, $C \in\left[C^{E D}, C^{P E}\right)$, and (iii) commercialization by sale occurs at sales price $S^{*}=v_{i i}$ if competition is sufficiently high, $C \in\left[C^{P E}, \bar{C}(i)\right)$.

Proposition 1 is proved below and is also illustrated in Figure 4.1. Figure 4.1(i) solves the acquisition entry game as a function of the intensity of competition, $C$. When the intensity of competition is low $\left.C \in(\bar{C}(e)), C^{E D}\right)$, the net value for entry deterrence is negative, i.e. an incumbent's entry deterring valuation is lower than the entrant's entry value, $v_{i e}-v_{e}<0$. Intuitively, at low competition, the opportunity cost of an acquisition is high for an incumbent.

What happens if competition increases? Differentiate $v_{i e}-v_{e}$ in $C$ to obtain

$$
v_{i e, C}^{\prime}-v_{e, C}^{\prime}=-\left(\frac{m-1}{m}\right) \frac{d \pi_{N}(e)}{d C}>0,
$$

where we use $v_{C}^{\prime}$ as the notation for the derivative, $\frac{d v}{d C}$.

Thus, the entry-deterring valuation of an incumbent $v_{i e}$ increases more than the entrepreneur's value of entry $v_{e}$ when competition increases. Note that the first term in $v_{i e}=$ $\pi_{A}(i)-\left(\frac{m-1}{m}\right) \pi_{N}(e)$ decreases with the same amount as the first term in $v_{e}=\pi_{E}(e)-F$, since the acquiring incumbent and the entrepreneur face the same negative effect of increased competition from Assumption A1. However, since the profit of a non-acquirer $\pi_{N}(e)$ decreases in $C$, this creates an increase in the incumbent's valuation, thereby implying that $v_{i e, C}^{\prime}>v_{e, C}^{\prime}$. Thus, since an incumbent's net value of entry deterrence $v_{i e}-v_{e}=F-\left(\frac{m-1}{m}\right)\left[\pi_{N}(e)-f\right]$ is increasing in competition $C$, an entry deterring acquisition at the acquisition price $S^{*}=v_{e}=\pi_{E}(e)-F$ occurs at $C=C^{E D}$, as shown in Figure 4.1(ii). Other incumbents will not preempt a rival acquisition in the region $C \in\left[C^{E D}, C^{P E}\right)$, since the net value of preemption is negative, $v_{i i}-v_{e}<0$.

However, note that increasing the intensity of competition further into the region, $C \geq C^{P E}$ will imply that the net value of preemption is strictly positive, $v_{i i}-v_{e}>0$. This induces a bidding war between incumbents driving the equilibrium sales price above the entry value for the entrepreneur, $S^{*}=v_{i i}=\pi_{A}(i)-\pi_{N}(i)>v_{e}$.

To complete the analysis, Figure 4.1(iii) shows how equilibrium ownership is jointly determined by the quality of the innovation $\bar{k}$ and the intensity of competition $C$. Let $k^{E D}\left(C^{E D}\right)$ be the takeover condition (TO-condition) defined from $v_{i e}\left(C^{E D}, \bar{k}\right)=v_{e}\left(C^{E D}, \bar{k}\right)$, and let $k^{P E}\left(C^{P E}\right)$ be the preemption condition (PE-condition) defined from $v_{i i}\left(C^{P E}, \bar{k}\right)=v_{e}\left(C^{P E}, \bar{k}\right)$. Differentiate $v_{i e}\left(C^{E D}, \bar{k}\right)=v_{e}\left(C^{E D}, \bar{k}\right)$ and $v_{i i}\left(C^{P E}, \bar{k}\right)=v_{e}\left(C^{P E}, \bar{k}\right)$ in $\bar{k}$ and $C$ to get: 


$$
\frac{d k^{E D}}{d C}=-\frac{\frac{d \pi_{N}(e)}{d C}}{\frac{d \pi_{N}(e)}{d k}}<0, \quad \frac{d k^{P E}}{d C}=-\frac{\frac{d \pi_{N}(i)}{d C}}{\frac{d \pi_{N}(i)}{d k}}<0,
$$

where $\frac{d \pi_{N}(l)}{d k}<0$ holds from Definition 1 and $\frac{d \pi_{N}(l)}{d C}<0$ holds from Definition 2.

The loci associated with the takeover condition $k^{E D}\left(C^{E D}\right)$ and the preemption condition $k^{P E}\left(C^{P E}\right)$ are downward-sloping in the $C-k$ space. Intuitively, at a higher intensity of competition $C$, a lower quality of the innovation is needed to balance the incumbent's higher value of obtaining the innovation (i.e. to preserve a zero net value $v_{i l}=v_{e}$ for $l=e . i$ ). The equilibrium ownership structure involves innovation for entry below the takeover locus $k^{E D}(C)$, indicated as $l^{*}=e$. Takeover acquisitions occur for combinations of $C$ and $k$ between the takeover locus $k^{E D}(C)$ and the preemption locus $k^{P E}(C)$, indicated as $l^{*}=i$ and $S^{*}=v_{e}$. Preemptive acquisitions occur above preemption locus $k^{P E}(C)$, as indicated by $l^{*}=i$ and $S^{*}=v_{i i}$. Thus, innovation for sale is conducive to markets where there is a high-quality innovation for sale and intense competition. Once more, this reflects a low opportunity cost of an acquisition, due to incumbents' weak position as non-acquirers.

\subsection{Why increased competition may increase the incentive to innovate under in- novation for sale}

Let us now examine how competition affects the entrepreneur's incentive to innovate. To highlight the effect of competition on innovation incentives, we maintain Assumption A1. The following proposition concerning innovation incentives for the entrepreneur is then immediate:

Proposition 2. Suppose that Assumption $A 1$ holds and $C^{E D}$ and $C^{P E}$ exist. Then: (i) the incentive to innovate for entry decreases when the intensity of competition $C$ increases, (ii) for $C \in\left[C^{P E}, \bar{C}(i)\right)$ the innovation incentives are stronger under innovation for sale than under innovation for entry, (iii) the incentive to innovate for sale can increase when the intensity of competition $C$ increases.

The proposition is proved in Figure 4.2, where Figure 4.2(iii) now depicts the reward of the entrepreneur $R_{E}(l)$ as a function of the intensity of competition $C$. When intensity of competition is low $\left.C \in(\bar{C}(e)), C^{E D}\right)$, innovation for entry occurs and the reward $R_{E}(e)=v_{e}=$ $\pi_{E}(e)-f-F$ for the entrepreneur. From Definition $2, R_{E}(e)$ is decreasing in competition and from Lemma 2 , innovation incentives are reduced. The same holds if an entry deterring acquisition occurs in region $C \in\left[C^{E D}, C^{P E}\right)$ since $R_{E}(i)=S^{*}=v_{e}$.

However, when competition is more intense $C \geq C^{P E}$ and preemptive acquisitions occur, the reward for innovation for sale is strictly higher than the reward for innovation for entry, $R_{E}(i)=v_{i i}>v_{e}=R_{E}(e)$ which, from Lemma 2, implies that the entrepreneur is more likely to succeed under innovation for sale, $\rho_{E}^{*}(i)>\rho_{E}^{*}(e)$.

The effect of increased intensity of competition on innovation incentives under innovation for sale is ambiguous since:

$$
\frac{d R_{E}(i)}{d C}=\frac{d S^{*}}{d C}=\frac{d \pi_{A}(i)}{d C}-\frac{d \pi_{N}(i)}{d C} \lesseqgtr 0
$$




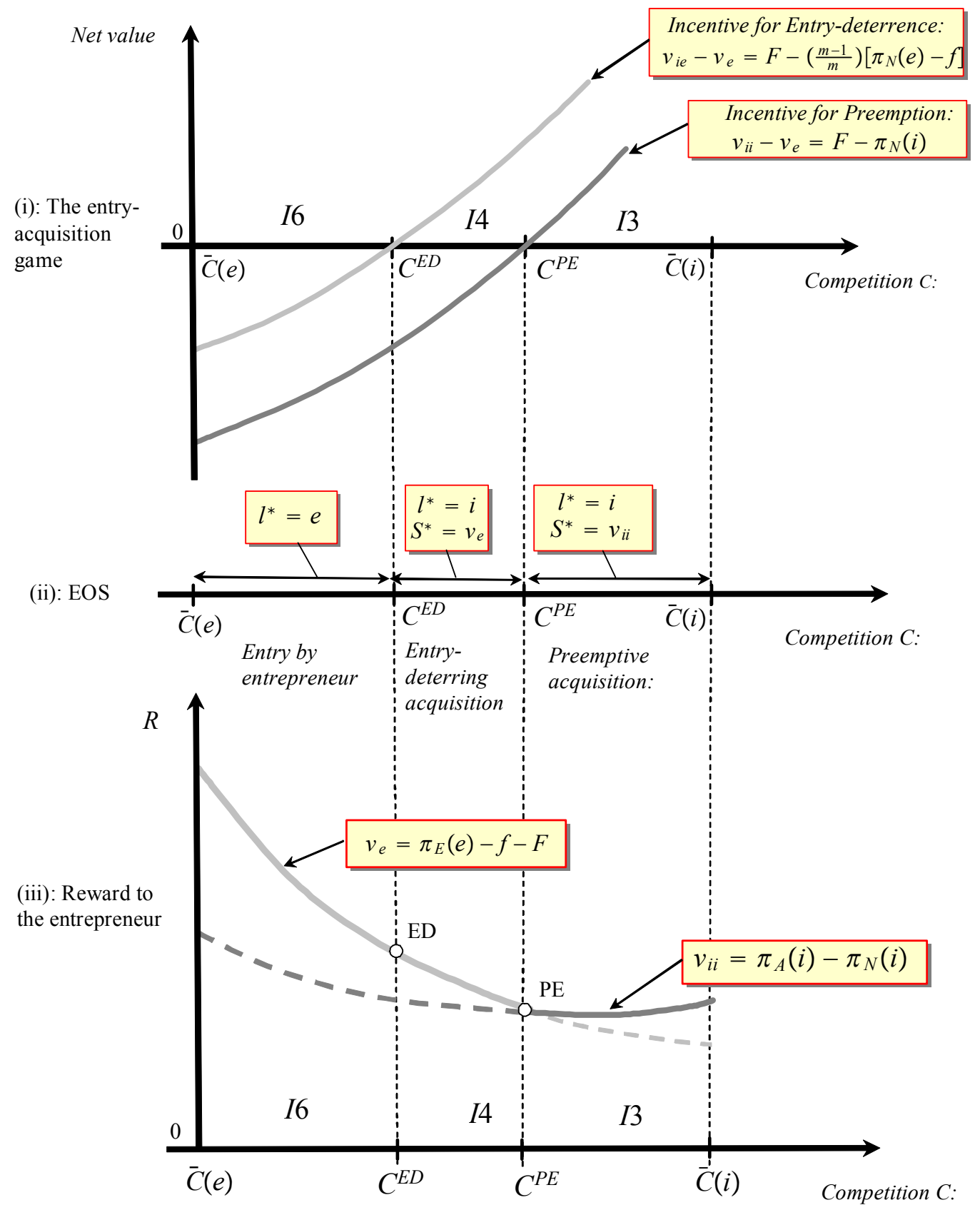

Figure 4.2: Entrepreneurial reward to innovation and the intensity of competition. 
In equilibrium, the acquisition price $S^{*}$ of the invention is a non-acquiring incumbent's willingness to pay $v_{i i}$, which consists of two profit terms: the product market profit for this firm if it were instead to obtain the invention $\pi_{A}(i)$, and the corresponding profit when not buying, $\pi_{N}(i)$, i.e. $S^{*}=\pi_{A}(i)-\pi_{N}(i)$. It then follows that the first profit term decreases when competition increases. However, the second profit term will also decrease, which implies that the willingness to pay can increase as well as decrease when competition increases, depending on which is the dominating effect.

Lemma 3 and Lemma 4 provide two examples where the incentive to innovate for sale increase when the intensity of competition $C$ increases.

Example 1 (Cournot competition with differentiated products (CDP Model)). The inverse demand of a firm of type $h=A, N, E$ is $P_{h}=a-q_{h}-\gamma q_{-h}$, where $\gamma \in[0,1]$ is the degree of product substitutability (where an increase in $\gamma$ makes firms' products closer substitutes), $q_{h}$ is firm $h$ 's output and $q_{-h}$ is the output of firm $h$ 's competitors. Thus, competition $C$ is measured through product substitutability $(\gamma)$ and/or through the number of incumbents $(n)$. This specification captures the fact that markets with only a few firms can be highly competitive, while competition can be weak in markets with a large number of firms (see Gilbert (2006)).

The product market profit for a firm of type $h$ (where, for brevity, we omit ownership $l$ on the right-hand side) is $\pi_{h}\left(q_{h}, q_{-h}, l\right)=\left(P_{h}\left(q_{h}, q_{-h}\right)-c_{h}\right) q_{h}$, where firms of different types have the following marginal costs:

$$
c_{E}=c-\bar{k}, \quad c_{A}=c-\bar{k}, \quad c_{N}=c .
$$

Let $q^{*}=\left(q_{h}^{*}, q_{-h}^{*}\right)$ be the Nash-Cournot equilibrium from the first-order conditions $\frac{\partial \pi_{h}}{\partial q_{h}}=P_{h}$ $+\frac{\partial P_{h}}{\partial q_{h}} q_{h}^{*}-c_{h}=0$ and let $\pi_{h}(l)=\left(P_{h}\left(q_{h}^{*}, q_{-h}^{*}(l), l\right)-c_{h}\right) q_{h}^{*}(l)$ be the associated reduced-form profit function. Differentiating $\pi_{h}(l)$ in $\gamma$, we obtain:

$$
\frac{d \pi_{h}(l)}{d \gamma}=\left[P_{h, \gamma}^{\prime}+P_{h, q_{-h}}^{\prime} \frac{d q_{-h}^{*}}{d \gamma}\right] q_{h}^{*}
$$

where $P_{h, \gamma}^{\prime}$ is the direct price effect and $P_{h, q_{-h}}^{\prime} \frac{d q_{-h}^{*}}{d \gamma}$ is a strategic price effect due to the change in competitors' output $\frac{d q_{-h}^{*}}{d \gamma}$. Definition 2 implies that firm h's price falls in competition. When increased competition is captured by making products more homogenous, holding the number of firms fixed, the acquisition price can nevertheless increase in competition. As shown in the Appendix, the reason is that the product market price for the acquirer (being a low-cost firm) is reduced less than for a non-acquiring rival (being a high-cost firm), since rivals of a low cost firm will reduce their output more than rivals of a high-cost firm. The smaller reduction in price even compensates for the fact that the price fall affects more units in the larger acquiring incumbent. Formally, assuming that fixed costs $f$ are such that Assumption A1 is fulfilled, we have the following Lemma which is proved in the Appendix:

Lemma 3. For $C=\gamma$, (i) $\frac{d \pi_{N}(l)}{d \gamma}<0$, (ii) $\frac{d \pi_{h}(l)}{d \gamma}<0$ for $h=A, E$ and (iii) $\frac{d S}{d \gamma}=\frac{d v_{i i}}{d \gamma}=$ $\frac{d \pi_{A}(i)}{d C}-\frac{d \pi_{N}(i)}{d C}>0$ for $\gamma \in\left[\gamma_{A}^{\min }, \tilde{\gamma}\right]$. 
Example 2 (Bertrand competition with differentiated products (BDP Model)). The inverse demand function in $P_{h}=a-q_{h}-\gamma q_{-h}$ can be inverted into direct demand $q_{h}(p)$ where $p=\left(p_{h}, p_{-h}\right)$. Deriving reduced-form profits $\pi_{h}(l)=\left(p_{h}^{*}-c_{h}\right) q_{h}\left(p^{*}\right)$ where $p^{*}$ is the Nashequilibrium in prices, we have

$$
\frac{d \pi_{h}(l)}{d \gamma}=\left[q_{h, \gamma}^{\prime}+q_{h, p_{-h}}^{\prime} \frac{d p_{-h}^{*}}{d \gamma}\right]\left(p_{h}^{*}-c_{h}\right),
$$

where the change in a firm's profit now depends on its output times its price-cost margin. Evaluating (4.7) is analytically cumbersome. Therefore, we give a numerical example where Lemma 3 is also fulfilled in the Bertrand model. This shown in Figure A.2 in the Appendix.

Lemma 4. For $C=\gamma$, there exist parameter values in the BDP model where (i) $\frac{d \pi_{N}(l)}{d \gamma}<0$, (ii) $\frac{d \pi_{h}(l)}{d \gamma}<0$ for $h=A, E$ and (iii) $\frac{d S}{d \gamma}=\frac{d v_{i i}}{d \gamma}=\frac{d \pi_{A}(i)}{d \gamma}-\frac{d \pi_{N}(i)}{d \gamma}>0$ for $\gamma \in\left[\gamma_{A}^{\min }, \tilde{\gamma}\right]$.

\subsection{Extensions}

So far, our results have been derived under the assumption that entry does not affect the number of firms on the market. This assumption is relaxed below.

\subsubsection{No exit}

Let us now turn to the case where entry leads to a less concentrated market structure, i.e. if a sale occurs there are $m$ active firms in the market, whereas if entry occurs, there are $m+1$ active firms in the market. To this end, we make the assumption:

Assumption A2 Entry without exit of incumbents: $C \in(0, \bar{C}(i))$.

Since all incumbents remain on the market, (4.1) becomes:

$$
v_{i l}-v_{e}=\left[\pi_{A}(i)-\pi_{E}(e)+F\right]-\left[\pi_{N}(l)-f\right], \quad l=\{e, i\},
$$

whereas the effect of changing intensity of competition from (4.8) becomes:

$$
v_{i e, C}^{\prime}-v_{e, C}^{\prime}=\left[\frac{d \pi_{A}(i)}{d C}-\frac{d \pi_{E}(e)}{d C}\right]-\frac{d \pi_{N}(l)}{d C} \gtreqless 0 \quad l=\{e, i\} .
$$

Thus, under Assumption A2, the innovation transfer effect is now affected by competition. However, since the effects on the entrant and the acquirer of an increase in intensity of competition differ, i.e. $\frac{d \pi_{A}(i)}{d C} \neq \frac{d \pi_{E}(e)}{d C}$, we cannot determine the sign of the effect of competition on the net value of an acquisition. To derive more detailed results, we once more use the CDP model:

Example 3 (CDP model with no exit). Consider the CDP model where entry by the entrepreneur now leads to a market structure with both more firms and more varieties of products. This implies that $\pi_{N}(e)<\pi_{N}(i)$ and thereby that, once more, the net value of entry deterrence is greater than the net value of preemption, $v_{i e}-v_{e}>v_{i i}-v_{e}$. We can then state the following Lemma which shows that Propositions 1 and 2 can hold under Assumption A2. 
Lemma 5. Under Assumption A2 in the CDP model, (i) commercialization by entry takes place for $\gamma \in\left(0, \gamma^{E D}\right)$, (ii) commercialization by sale occurs at sales price $S^{*}=v_{e}$ for, $\gamma \in\left[\gamma^{E D}, \gamma^{P E}\right)$, (iii) commercialization by sale occurs at sales price $S^{*}=v_{i i}$ for $\gamma \in\left[\gamma^{P E}, \bar{\gamma}(i)\right)$ and (iv) sales price $S^{*}=v_{i i}$ increases in $\gamma$ for some $\gamma \in\left[\gamma^{P E}, \bar{\gamma}(i)\right)$.

Proof. See the Appendix

Thus, increasing the intensity of competition in the differentiated Cournot model, by making products closer substitutes, will once more lead to a move from an equilibrium with innovation for entry to one with innovation for sale, and the acquisition price and, hence, the innovation incentives can increase when competition is intensified.

\subsubsection{Multiple-incumbent exits}

Let us now discuss what will happen if entry leads to more than one incumbent firm exiting the market. To this end, we make the following assumption:

Assumption A3 Entry leading to multi-firm exit: $C \in\left(\bar{C}(e), C^{\max }\right)$.

In this case, the net value of an acquisition defined in (4.1) becomes:

$$
v_{i l}-v_{e}=F-\lambda(l)\left[\pi_{N}(l)-f\right], \quad l=\{e, i\} .
$$

Note that the innovation transfer effect is once more given from the fixed cost savings $F$, since the number of firms is the same regardless of commercialization strategy $n(i)=n(e)$ when $C>\bar{C}(e)$ which implies that $\pi_{A}(i)=\pi_{E}(e)$. Thus, the pattern of commercialization of the innovation is once more given from how competition affects the opportunity cost of an acquisition.

Under Assumption A3, we cannot directly determine the sign of the effect of competition on the net value of an acquisition and hence, the effect of the commercialization pattern is ambiguous. The reason is that while increased intensity of competition decreases the nonacquirer's profit as long as exit does not occur, it will have the opposite effect exactly at the point where exit occurs. The reason is that at that point, the non-acquirer's profit increases from zero (where exit occurs) to positive. However, it should be noted that the number of active non-acquirers in the market becomes smaller and will become zero at monopoly where we refer to this level of competition as $C^{\text {mon }}$. This implies that while there would be situations where small changes in competition imply that we move from an equilibrium of commercialization by sale to one with commercialization by entry, commercialization by sale will prevail when the intensity of competition becomes sufficiently strong, i.e. $v_{i l}-v_{e}=F$ at $C=C^{m o n}$. Consequently, we can state the following result:

Proposition 3. For sufficiently high intensity of competition, there will be innovation for sale, i.e. there exists a $C^{H}>0$ such that for $C \in\left(C^{H}, C^{m o n}\right), l^{*}=i$.

Let us end this section by examining the CDP model in a setting without restrictions on entry and exits. 
Example 4 (CDP model under A1, A2 and A3). Figure 4.3 illustrates the equilibrium over the full range of level of intensity of competition, i.e. over A1, A2 and A3. In particular, it illustrates that the innovation for sale is conducive to high intensity of competition $\gamma$ (since products become closer substitutes) and that the reward for innovation for sale can increase in intensity of competition, $\gamma$.

\section{Merger policy}

Here, we study the effects of merger policy on the pattern of innovation for sale and entry, and on the incentive to innovate. In most countries, the basic practice of merger policy implies that mergers increasing the level of concentration in the market too much will be blocked, unless there is likely to be some counter effect, for example new entry, making the market power increase associated with the merger less strong. To capture the basics of such merger policies, we will here assume that the policy maker simply decides on the minimum number of firms allowed in the market; mergers leading to market structures with too few firms will then be blocked. Even though this stylized policy abstracts from important features of merger policy in practice ${ }^{22}$, we believe that this exercise captures important effects of merger policy on the innovation incentive for outsiders to the industry. In this vein, it captures long-run innovation effects of sustaining a "specific level of competition" in the industry. ${ }^{23}$

To this end, we modify the model in the following way: In stage 0 , the government commits to the minimum number of firms allowed in industry $n$. We assume there to be a merger formation game in stage 1 such that the resulting market structure consists of $n \leq m$ incumbent firms in the market. We assume that if there is entry by the entrepreneur in stage 3 , there will be an additional merger by two incumbents in stage 4, as firms react to maintain the level of concentration allowed by the merger policy. Thereby, the merger policy in stage 0 determines the number of firms active in the market in stage 4. Thus, merger policy "replaces" the exit condition (3.3). To keep the model tractable, we assume that one of the firms is closed down in a merger, i.e. we assume that mergers are driven by market power increases and fixed cost savings, $f$. The effects of allowing for a more elaborate merger formation model are discussed in Section 6. As in the previous section, we solve the game backwards.

\subsection{Why a stricter merger policy may lead to innovation for sale}

Let us first examine how merger policy will affect the mode of commercialization chosen by the entrepreneur.

First, note that when entry occurs, two incumbents will merge in stage 4 since such a

${ }^{22}$ Note that after the innovation, with only one firm holding the superior technology, the market structure will differ from the pre-innovation equilibrium even if the number of firms is the same. In principle, "the minimum number of firms allowed in the industry" will then depend on the level of asymmetry. Taking such aspects into account is, however, left to future research.

23 See Motta (2004) for an overview of the practice and a theory of merger policy.

The complexity of the externalities involved in the mergers and investments indicates that informational constraint will be important for deriving optimal merger policy. An interesting step is then to explicitly model this restriction and investigate whether policies resulting in a higher welfare level might be found. 


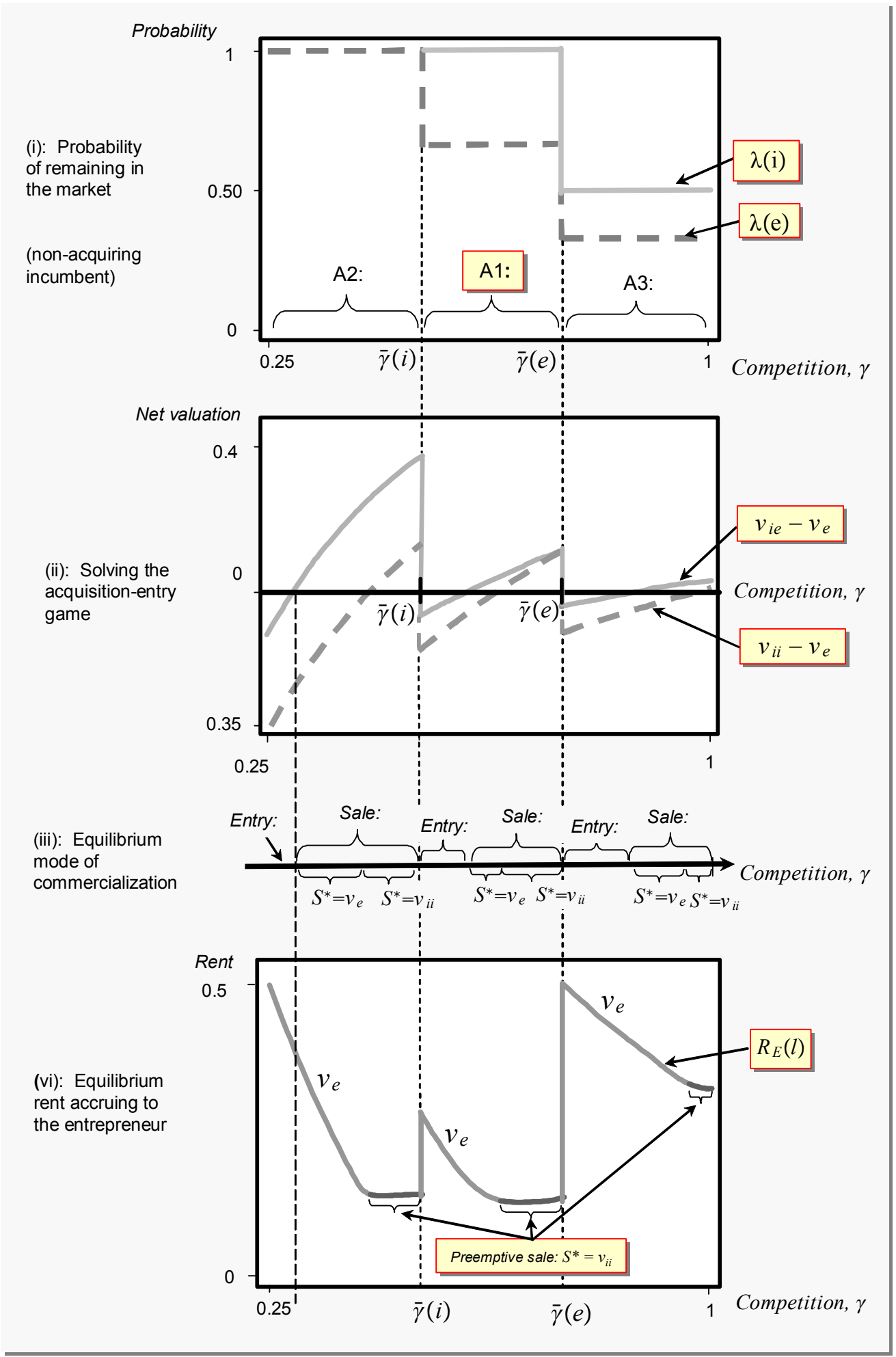

Figure 4.3: A full solution of the DPC model. Paremeter values at $m=3, a=4, c=1, \bar{k}=0.1$, $F=0.1$ and $f=0.7$. 


\section{Government $G$ chooses the strictness of competition policy $r$}

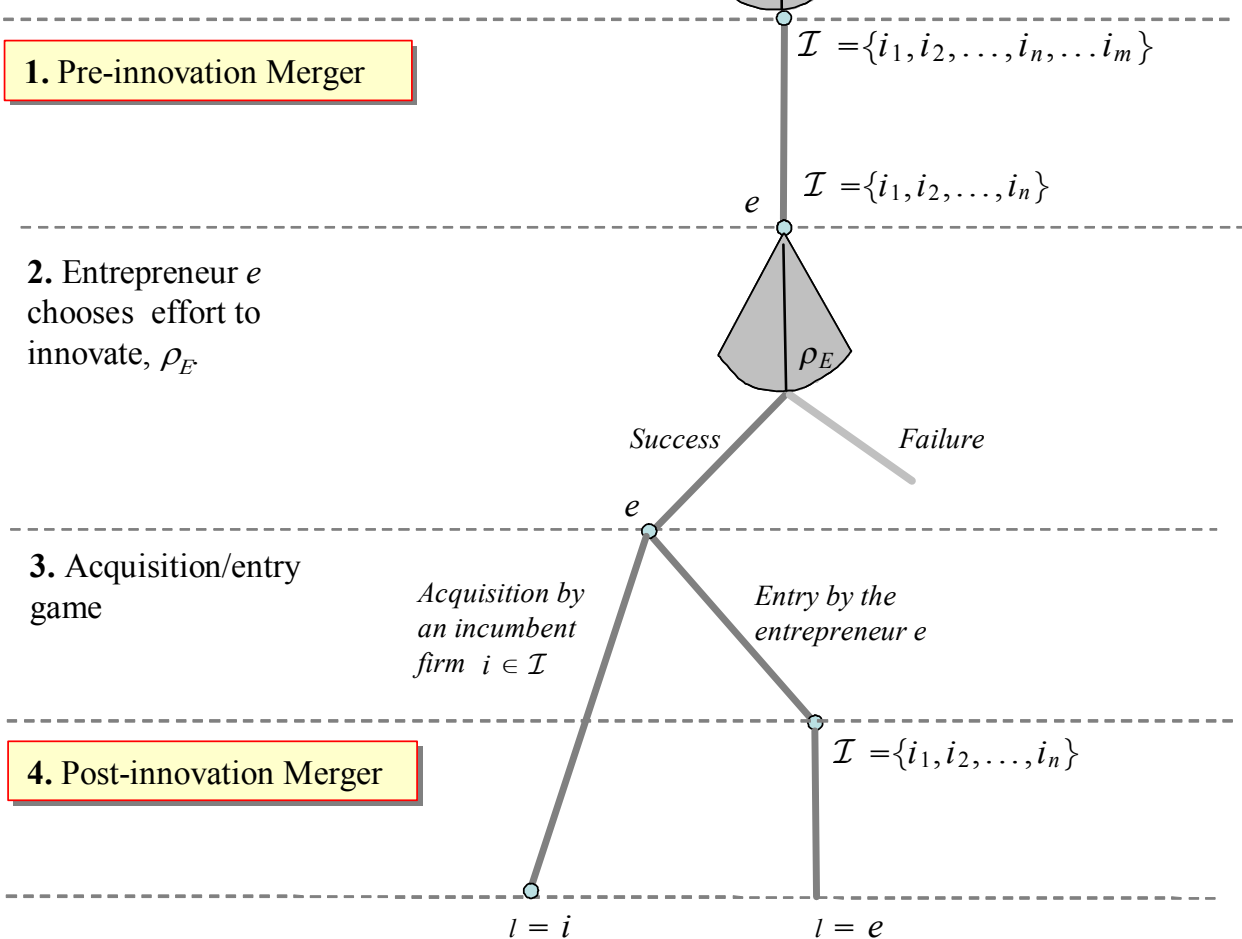

5. Product market interaction, $x_{j}$

Figure 5.1: The extended game with competition policy. 
merger will now be allowed under the merger policy. Thus, the total number of firms is always $n$, regardless of whether the entrepreneur chooses to enter or sell, as the market forces continue to generate mergers up to the limit allowed by the merger law. It then follows that the entering entrepreneur obtains exactly the same market position as would the acquiring firm in case of a sale of the innovation, i.e. $\pi_{E}(e)=\pi_{A}(i)$. Moreover, the successful non-acquiring incumbents obtain the same market position under entry and sale and thus, we have $\pi_{N}(e)=\pi_{N}(i)$.

Then, note that a non-acquiring incumbent's expected profit in stage 3 , when there is innovation for entry by the entrepreneur, is:

$$
\mathrm{E}\left[\pi_{N}(e)\right]=\underbrace{\frac{1}{n}\left[\pi_{N}(e)-f-\Phi\right]}_{\text {Exp. profit as acquirer }}+\underbrace{\left[1-\frac{1}{n}-\left(1-\frac{2}{n}\right)\right] \Phi}_{\text {Exp. profit as seller }}+\underbrace{\left(1-\frac{2}{n}\right)\left[\pi_{N}(e)-f\right]}_{\text {Exp. profit as non-acq. }}
$$

where $\Phi$ is a transfer or the acquisition price in the merger between the two incumbents in stage 4 .

Simplifying, we have that $\mathrm{E}\left[\pi_{N}(e)\right]=\left(\frac{n-1}{n}\right)\left[\pi_{N}(e)-f\right]{ }^{24}$ Hence, the net value of an acquisition for incumbents from (4.1) in stage 3 can be written:

$$
v_{i l}-v_{e}=\left\{\begin{array}{c}
v_{i e}-v_{e}=F-\left(\frac{n-1}{n}\right)\left[\pi_{N}(e)-f\right], \quad l=e \\
v_{i i}-v_{e}=F-\pi_{N}(i), \quad l=i .
\end{array}\right.
$$

To proceed, we make the following assumption:

Assumption A4 The expected profit for a non-acquirer $\mathrm{E}\left[\pi_{N}(e)\right]=\left(\frac{n-1}{n}\right)\left[\pi_{N}(e)-f\right]$ is decreasing in the number of firms active in the market

From Definition $2, \pi_{N}(e)$ is decreasing in $n$. However, the probability of being a nonacquirer $\left(\frac{n-1}{n}\right)$ is increasing in $n$ and therefore, the effect of increased competition on the expected profit of a non-acquirer $\left(\frac{n-1}{n}\right)\left[\pi_{N}(e)-f\right]$ cannot be unambiguously determined. However, straightforward calculations show that Assumption A4 holds in the CDP model. ${ }^{25}$

Substituting $C^{E D}=n^{E D}$ and $C^{P E}=n^{P E}$ (ignoring the integer problem) in Definition 4 and using the same reasoning as in the proof of Proposition 1, we can then state the following Proposition:

Proposition 4. Assume that $A 4$ holds and $n^{E D}$ and $n^{P E}$ exist, then (i) commercialization by entry takes place if merger policy is non-strict, $n \in\left(1, n^{E D}\right)$, (ii) commercialization by sale occurs at sales price $S^{*}=v_{i i}$ or no sale takes place when merger policy is medium-strict, $n \in\left[n^{E D}, n^{P E}\right)$, and (iii) commercialization by sale occurs at sales price $S^{*}=v_{i i}$ if the merger policy is very strict, $n \in\left[n^{P E}, m\right]$.

Consequently, we have shown that the incentive for innovation for sale relative to innovation for entry will increase with a stricter merger policy. The stricter merger policy reduces the

\footnotetext{
${ }^{24}$ A merger between non-acquiring incumbents is profitable if the condition $\pi_{N}(e)-f-\left(\pi_{N}^{-}(e)-f\right)>$ $\left(\pi_{N}^{-}(e)-f\right)$, where $\pi_{N}^{-}(e)$ is the profit for a non-acquiring incumbent when no merger takes place. This condition is fulfilled for some $f \in\left(0, \pi_{N}^{-}(e)\right)$, since $\pi_{N}(e)>\pi_{N}^{-}(e)$.

${ }^{25}$ Proofs are available from the authors upon request.
} 
profit for all firms in the market. In particular, it reduces it equally for the entrant as for the acquirer. But the opportunity cost for the acquirer decreases since he is then worse off as a non-acquirer.

\subsection{The incentive for innovation for sale and merger policy: an inversely U-shaped relationship}

Let us now turn to how the merger policy affects the incentive to innovate. To this end, we use the CDP model. First, it can be shown that the entry profit decreases when the number of firms in the industry increases in the CDP model. Consequently, the incentive for innovation for entry will be lower under the strict merger policy.

Second, in Appendix 5, it is shown that the acquisition price decreases when the number of firms in the industry increases when $n \geq 2$, since the acquirer's product market profit decreases more than the non-acquirer's profit. Thus, a strict merger policy reduces the incentive for innovation for sale when $n \geq 2$. However, if the merger policy prevents full monopolization, i.e. $n=1$, things look different. A strict merger policy will then have a positive effect on the incentive for innovation for sale. To see this, note that if $n=1$, the acquisition price is $S^{*}=\epsilon$, whereas if $n=2 S^{*}=\pi_{A}(i)-\pi_{N}(i)>\epsilon$. Thus, when full monopolization is prevented by the merger policy, the acquisition price will be increased. The reason is that here, increased competition implies the innovator's bargaining position to be significantly improved, because the buyers then start competing to acquire the innovation.

However, it should be noted that the auction set up without a reservation price in this situation is less compelling and with a bargaining framework, the total effect on the sales price going from duopoly to monopoly would be ambiguous. The effect of increasing the bargaining power of the entrepreneur going from one to two incumbents would still be there, however.

These effects are illustrated in Figure 5.2 where the number of firms is a discrete variable. Increasing the number of firms in very concentrated markets increases the incentive for innovation for sale, whereas increasing the number of firms in less concentrated markets leads to a reduced incentive for innovation for sale, thereby leading to an inversely U-shaped incentive for innovation when increasing the intensity of competition by increasing the number of firms.

Consequently, we have derived the following result:

Proposition 5. In the CDP model: (i) the incentive to innovate for entry will be reduced under a strict merger policy. (ii) The incentive to innovate for sale will be increased under a strict merger policy in very concentrated markets, i.e. when the number of incumbent firms increases from monopoly to duopoly. (iii) For $n \geq 2$, the incentive to innovate for sale will be reduced under a strict merger policy.

\section{Robustness}

We here explore how our results are affected by allowing the entrepreneur to sell licences of a patent of its innovation and allowing for asymmetric firms. 


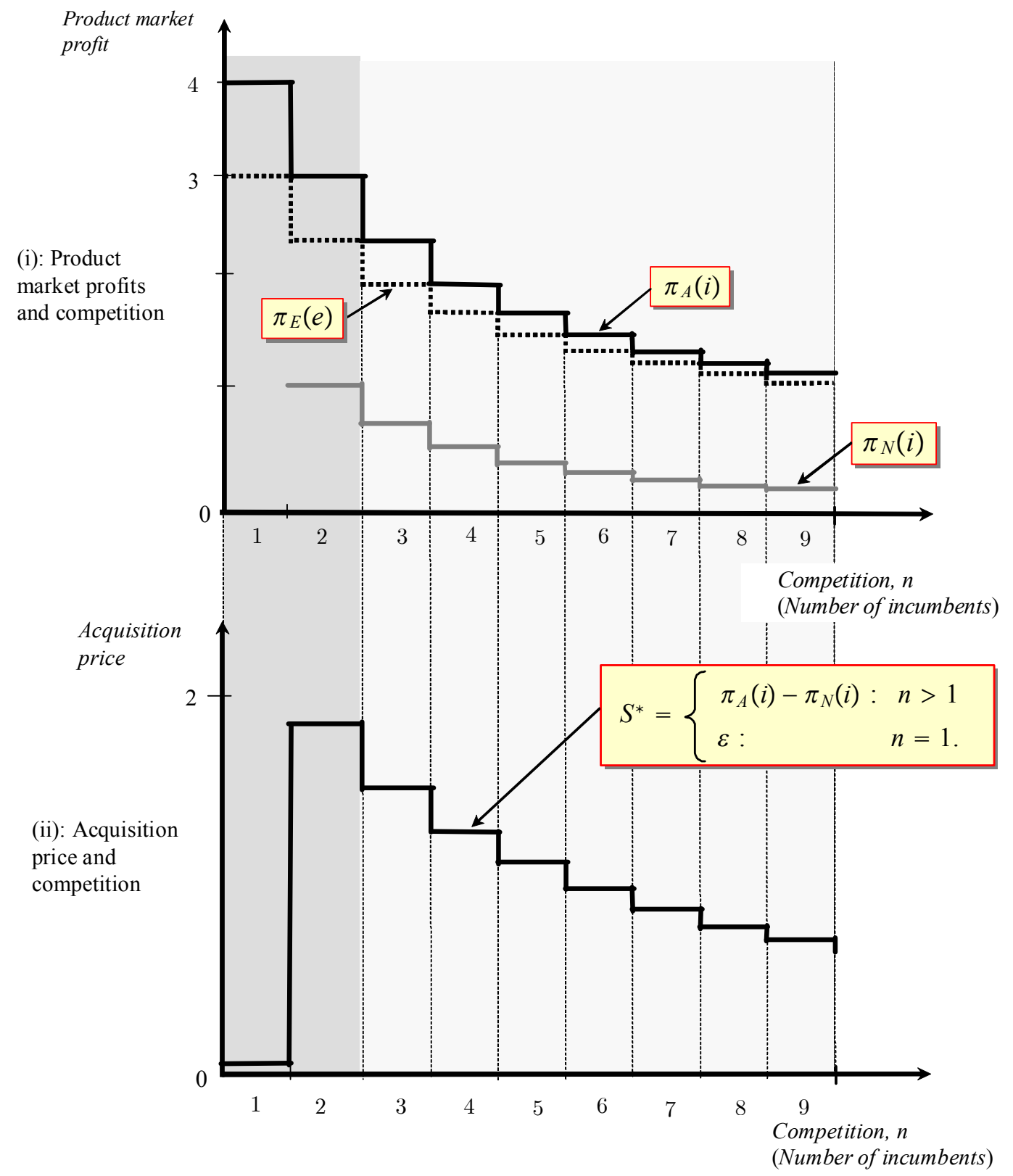

Figure 5.2: Illustrating Proposition 5. Profits and sales price as a function of merger policy. Parameter values at $\Lambda=3, \gamma=0.5$ and $\bar{k}=1$. 


\subsection{Exclusivity}

In the analysis, we have assumed that the seller can only sell the innovation (or the innovative firm) exclusively to one buyer. In many cases, the "innovation" consists of a combination of assets in terms of capital, intellectual capital, and human capital, which cannot be used by many firms simultaneously. Multi-firm licensing is then not an option. Indeed, we observe many acquisitions of such small innovative firms by large incumbents. An example is Cisco's acquisition of Cerent at the price of $\$ 6.9$ billion.

However, in some situations, several buyers might hold a licence to utilize the innovations. In such situations, the seller might consider how many licences to sell. This issue is studied in the literature on patent licensing. Kamien and Tauman (1986) assume that the independent innovator acts as a standard monopolist, by posting a price and allowing the buyers to decide whether to buy a licence. Then, they show that the number of licences is falling in the quality of the innovation in such a setting. Allowing the seller to commit to the number of licences to sell, Katz and Shapiro (1986) show that there exists an equilibrium where some potential buyers are left without a licence. Consequently, the mechanisms identified here, which crucially depend on some firms facing the risk of becoming non-acquirers, are present also when multi-firm licensing is possible. To see this, consider the following extension where the entrepreneur can decide on how many licences $r$ to licence if not entering. We then consider the Cournot model in stage 3 with differentiated products with $m$ incumbents. Let $\pi_{A}(i, r)$ denote the profit of a buyer of a licence when there are $r$ licenses for sale. Let $\pi_{N}(i, r)$ be the profit of a firm not buying a licence. Licensing by the entrepreneur gives the profit $\Omega=r\left[\pi_{A}(i, r)-\pi_{N}(i, r)\right]$. Treating $r$ as continuous, the optimal number of licenses is:

$$
\Omega_{r}^{\prime}=\underbrace{\left[\pi_{A}(i, r)-\pi_{N}(i, r)\right]}_{(+)}+r\left[\pi_{A, r}^{\prime}(i, r)-\pi_{N, r}^{\prime}(i, r)\right]=0 .
$$

It can be shown that $\pi_{A, r}^{\prime}(i, r)-\pi_{N, r}^{\prime}(i, r)<0, \pi_{A, r}^{\prime}(i, r)<0$ and $\pi_{N, r}^{\prime}(i, r)<0$, since more licenses increase aggregate output and lower the product market price, which affects a larger firm more. Assuming that $\Omega_{r r}^{\prime \prime}<0$ and $m$ is sufficiently large, there exists an optimal $r^{*}<m$.

How does competition affect the choice between licensing and entry? Define $\Omega^{*}\left(r^{*}\right) \equiv$ $r^{*}\left[\pi_{A}\left(i, r^{*}\right)-\pi_{N}\left(i, r^{*}\right)\right]$. This gives:

$$
\begin{aligned}
\frac{d \Omega^{*}}{d \gamma} & =\Omega_{r}^{\prime} \frac{d r^{*}}{d \gamma}+\frac{\partial \Omega^{*}}{\partial \gamma} \\
& =r^{*}\left[\frac{d \pi_{A}\left(i, r^{*}\right)}{d \gamma}-\frac{d \pi_{N}\left(i, r^{*}\right)}{d \gamma}\right]
\end{aligned}
$$

since $\Omega_{r}^{\prime}=0$ from (6.1). Once more, we may then have that $\frac{d \Omega^{*}}{d \gamma}>\frac{d v_{e}}{d \gamma}<0$ since $\frac{d \pi_{N}\left(i, r^{*}\right)}{d \gamma}<0$.

However, Erutku and Richelle (JEMS 2007) and Sen and Tauman (GEB 2007) show that if more sophisticated contracts can be used in an environment without appropriation problems, the entrepreneur might have an incentive to licence to all incumbents. An interesting future extension would be to endogenize when more sophisticated contracts are available and then how many licenses an entrepreneur would sell. 


\subsection{Synergies between invention and incumbent assets}

Consider the case where there is a synergy $s$ between incumbent assets and the invention. This will imply that the incumbent can use the invention more efficiently, i.e. $\frac{d \pi_{A}(i)}{d s}>0$ and $\frac{d \pi_{N A}(i)}{d s}<0$. It then follows that when the synergy $s$ increases, there is also an increase in the entry deterring valuation $v_{i e}$ and the preemptive valuation $v_{i i}$. Moreover, it follows that, at sufficiently high synergies, the preemptive valuation increases more since:

$$
\frac{d v_{i i}}{d s}-\frac{d v_{i e}}{d s}=-\frac{d \pi_{N A}^{D}(i)}{\underset{(-)}{d s}}>0 .
$$

$v_{i i}>v_{i e}$ holds for sufficiently high synergies and thus, we might have a situation where $v_{i i}>$ $v_{e}>v_{i e}$ with preemptive acquisitions taking place in equilibrium. This illustrates why the classical Salant et al. (1983) merger condition is not a necessary condition for an acquisition in our setting.

Thus, we make the following observation:

Proposition 6. At sufficiently high synergies between incumbent assets and the invention s, the inequality I2 $v_{i i}>v_{e}>v_{i e}$ in table 3.1 will hold. A preemptive acquisition can then take place in equilibrium, despite the classical Salant et al. merger condition, $v_{i e}>v_{e}$ not being fulfilled.

\subsection{Asymmetric firms}

What would happen if we allowed for asymmetric firms? In such a situation, incumbents will have different valuations of the innovation, and the auction game will, in general, be very tedious to solve since one needs to keep track of many possible orderings of valuations. However, a sufficient condition for commercialization by sale is then that there exists at least one incumbent $d \in \mathcal{I}$ for which the net value of a take-over acquisition is positive, i.e. $v_{i e}^{d}-v_{e}>0$, where:

$$
v_{i e}^{d}-v_{e}=\left[\pi_{A}^{d}(i)-\pi_{E}(e)+F\right]-\lambda^{d}(\mathrm{e})\left[\pi_{N}^{d}(e)-f\right] .
$$

The main difference from the above analysis is that the effects on the entrant's profit $\pi_{E}(e)$ and firm $d$ 's profit $\pi_{A}^{d}(i)$ of an increase in the intensity of competition might now differ also when exit(s) occurs. However, as long as $\frac{d \pi_{A}^{d}(i)}{d C}$ is not sufficiently more negative (or more positive) than $\frac{d \pi_{E}(e)}{d C}$, an increased intensity of competition (or a more restrictive merger policy) will be conducive to innovation for sale since $\frac{d \pi_{N}^{d}(l)}{d C}$ is still negative. Note that with asymmetric firms, an increase in the intensity of competition will often increase the profits of the more efficient firms. ${ }^{26}$ However, our result carries over also to this case as long as the relations described above hold.

\footnotetext{
${ }^{26}$ See Boone (2007). In the CDP model, when competition is initially very strong, the profits of the acquiring incumbent or the entrepreneurial firm will increase in competition. Since the profit of a nonacquiring incumbent always decreases in competition, innovation incentives under innovation for sale will then be even stronger. This is illustrated in Figure A.1.
} 
Moreover, if firms are asymmetric as non-acquirers, the exit game will look different. The most inefficient incumbent(s) would know that it (they) would exit if not acquiring when the intensity of competition is sufficiently high. This would then imply that sale would always be the equilibrium outcome, if entry were to trigger exit(s), i.e. $\lambda(e)=0$ for the inefficient incumbent(s).

We have also assumed that one of the firms is closed down in a merger between incumbents. What would happen if we used a more elaborate merger formation model? The initial merger process would then create asymmetric incumbents pre-innovation. As above, this would imply that as long as $\frac{d \pi_{A}^{d}(i)}{d C}$ is not sufficiently more negative than $\frac{d \pi_{E}(e)}{d C}$, increased intensity of competition (a more restrictive merger policy) would be conducive to innovation for sale since $\frac{d \pi_{N}^{d}(l)}{d C}$ is still negative.

\section{Concluding discussion}

We have shown that increased intensity of competition increases the relative profitability of innovation for sale relative to innovation for entry. Increased competition reduces entrants' and acquirers' profits in a similar fashion, but also reduces the profit when not acquiring. Incumbents' willingness to pay for the innovation therefore decreases less (increases) and thereby, the entrepreneur benefits from selling.

We have also shown that a stricter, but not too strict, merger policy tends to increase the incentive for innovations for sale by ensuring the bidding competition for the innovation, without reducing the total rents for innovations too much.

Consequently, the fear that increased competition (stricter competition policy) risks harming incentives to innovate seems less motivated when taking into account that entrepreneurs can sell their innovations.

In the previous literature, it has been shown that how product market competition affects the incentive for inhouse (incumbent or entrant) innovation depends on how competition affects the difference between a firm's profits in the market with an innovation and the profit it makes in the market absent the innovation. Policies increasing the intensity of competition in the market absent innovations will then stimulate the incentive for innovation through the so-called "escape-competition effect". ${ }^{27}$

We instead study how increased competition affects the incentive to innovate for sale. The equilibrium sales price of an invention is determined by the difference between an incumbent's profits as an acquirer and its profits as a non-acquirer. This implies that the profits in the pre-innovation market do not affect the incentive to innovate for sale. Consequently, in markets where innovation for sale is important, non-expected discretionary policy changes increasing competition in the market absent the innovation may have small effects on the innovation incentives. Committed long-run policies, balancing the need for differentiating profits between firms acquiring the top notch innovation and non-acquiring firms' profits, and the need for product market competition, instead seem more suitable for stimulating the incentive for innovation for sale.

\footnotetext{
${ }^{27}$ See Aghion et al. (2005) and Arrow (1962).
} 
Aghion et al. (2005) empirically document an inverted U-shaped relationship between product market competition and innovation in the UK, using the privatizations during the Thatcher regime, the EU single-market program, and the investigations performed by the Monopoly and Merger Commission to instrument for changes in competition. They also provide a theoretical model explaining this pattern. In their model, the incentive for innovation can increase when the intensity of competition increases since pre-innovation profits are reduced more than post-innovation profits. This "escape competition effect" stimulates innovations, particularly in industries where firms are operating at similar technology levels. However, in more laggard industries, competition reduces innovative activities. An inverted U-shaped relationship between competition and innovation is then due to the composition of laggard and technologically advanced industries. In our model, the inverted U-shaped relationship between competition and innovation is instead due to how the difference between the profit as an acquirer of the innovation and the profit as a non-acquirer is affected by changes in competition in a single industry. In particular, we derive such an inversely U-shaped relationship on the innovation for sale of stricter merger policy.

Another testable prediction of the model is that a country with a higher intensity of competition, such as the US, would have a higher share of innovation for sale over innovation for entry than a country with a low intensity of competition, like an EU country say. Yet another prediction is that countries implementing stricter merger policies, such as EU countries in the 1990s, should experience more innovation for sale relative to innovation for entry. More generally, our model suggests that different aspects of competition and competition policy can have very different empirical implications on the innovation pattern. 


\section{References}

[1] Acs, Z. J. and Audretsch D. B., 2005, "Entrepreneurship, Innovation and Technological Change, "Foundations and Trends in Entrepreuneurship, Vol 1, No 4, 149-195.

[2] Aghion, P. and P. Howitt, 1996, Endogenous Growth Theory, Cambridge: MIT Press.

[3] Aghion, P., C. Harris, P. Howitt, J. Vickers, 2001, "Competition, Imitation and Growth with Step-by-Step Innovation", Review of Economic Studies 68:3, 467-492.

[4] Aghion, P., N. Bloom, R. Blundell, R. Griffith, P. Howitt, 2005, "Competition and Innovation: An Inverted U-relationship", Quarterly Journal of Economics 120:2, 701-728.

[5] Aghion, P and Schankerman, 2004, "On the Welfare Effects and Political Economy of Competition-Enhancing Policies, Economic Journal, v114, n498: 800-824.

[6] Anton, J.J. and D.A.Yao, 1994, "Expropriation and Invention: Appropriable rents in the absence of property rights, "American Economic Review, 84(1), pp.190-209.

[7] Arrow, Kenneth, J., 1962. "Economic welfare and the allocation of resources forinventions" in Nelsson Richard R. (Eds.), The Rate and Direction of Technological Change. Princeton University Press, Princeton.

[8] Baumol, W.J., 2002, The Free-Market Innovation Machine: Analyzing the Growth Miracle of Capitalism, Princeton: Princeton University Press.

[9] Baumol W. J., 2004, Entrepreneurial Enterprises, Large Established Firms and Other Components of the Free-Market Growth Machine," Small Business Economics, Volume 23, Number 1, 9 - 21.

[10] Bernheim, B. D., and Whinston, M. D., 1998, "Exclusive Dealing, " Journal of Political Economy, 106(1), 64-103.

[11] Bianchi, M. and Henrekson M., 2005, "Is Neoclassical Economics Still Entrepreneurless?", Kyklos, Vol. 58, No. 3.

[12] Blundell, R., R. Griffith, J. van Reenen, 1996, "Dynamic Count Data Models of Technological Innovations", Economic Journal vol. 105, 333-344.

[13] Blundell, R., R. Griffith, J. van Reenen, 1999, "Market Share, Market Value and Innovation in a Panel British Manufacturing Firms", Review of Economic Studies vol. 66, 529-554.

[14] Boone, J., 2001, "Intensity of competition and the incentive to innovate", International Journal of Industrial Organization, 19, 705-726.

[15] Boone, J., 2007,'A new way to measure competition', Economic Journal, forthcoming.

[16] Chan, T., Jack A. Nickerson and Hideo Owan, 2009, "Strategic Management of R\&D Pipelines with Co-Specialized Investments and Technology Markets," forthcoming in Management Science. 
[17] Compte, O., Jenny, F., and Rey, P., 2002, "Capacity Constraints, Mergers and Collusion", European Economic Review v46, n1, 1-29.

[18] De Roos, N., 2004, "A Model of Collusion Timing", International Journal of Industrial Organization vol. 22:3, March, 351-387.

[19] Disney, R., Haskell, J., Heden, Y., 2000, "Restructuring and Productivity Growth in UK Manufacturing", Economic Journal vol. 113, July, 666-694.

[20] Gans, J.S. and S. Stern, 2000, "Incumbency and R\&D incentives: Licensing the gale of creative destruction," Journal of Economics and Management Strategy, 9 (4), pp. 485-511.

[21] Gans, J.S., D.H. Hsu, S. Stern, 2002, "When does Start-Up Innovation Spur the Gale of Creative Destruction?", RAND Journal of Economics vol. 33:4, 571-586.

[22] Gans, J.S. and S. Stern, 2003, "The Product Market and the Market for "Ideas": Commercialization Strategies for Technology Entrepreneurs", Research Policy vol. 32:2, 333-350.

[23] Gilbert, .R., 2006, Looking for Mr. Schumpeter: Where Are We in the CompetitionInnovation Debate?, Innovation Policy and the Economy, p. 159-215, Volume 6, Adam B. Jaffe, Josh Lerner and Scott Stern, editors, The MIT Press.

[24] Gilbert, Richard, and David M. G. Newbery (1982). "Preemptive Patenting and the Persistence of Monopoly." American Economic Review, 72, 514-26.

[25] Gilbert, Richard, and David M. G. Newbery (1992). "Alternative Entry Paths: The Build or Buy Decision" Journal of Economics 83 Management Strategy, vol. 1, N. 1, 129-150.

[26] Granstrand, O. and S. Sjölander, 1990, "The Aquisition of Technology and Small Firms by Large Firms", Journal of Economic Behavior and Organization vol. 13, 367-386.

[27] Hall, B.H., 1990, "The Impact of Corporate Restructuring on Industrial Research and Development", Brookings Papers on Economic Activity: Microeconomics 1990, 85-124.

[28] Hall, B.H. and R.H. Ziedonis, 2001. "The Patent Paradox Revisited: An Empirical Study of Patenting in the US Semiconductor Industry, 1979-95," Rand Journal of Economics, 32(1): 101-128.

[29] Jehiel, P., Moldovanu, B., and Stacchetti, E.,1996, "How (Not) to Sell Nuclear Weapons," American Economic Review, Vol. 86, 814-829.

[30] Jehiel, P, Moldovanu, B and Stacchetti, E (1999), Multidimensional Mechanism Design for Auctions with Externalities, Journal of Economic Theory, vol. 85(2), pages 258-293, April.

[31] Jehiel, P., Moldovanu, B (2000), Auctions with Downstream Interaction Among Buyers, RAND Journal of Economics, vol. 31(4), pages 768-791, Winter.

[32] Lerner, J. and R. Merges, 1998, "The Control of Strategic Alliances: an Empirical Analysis of the Biotechnology Industry", Journal of Industrial Economics vol. 46, 125-156. 
[33] Kamien, M.I. and Tauman Y., 1986, "Fees versus Royalties and the private value of a patent," Quarterly Journal of Economics, 472-491.

[34] Katz, M. L. and Shapiro C, 1986, "How to licence intangible property", Quarterly Journal of Economics, Vol. 101, No. 3, 567-590. Aug.

[35] Katz, M. L. and Shelanski H. A., 2005, "Merger Policy and Innovation: Must Enforcement Change to Account for Technological Change?," p. 109-165, Innovation Policy and the Economy, Volume 5, edited by Adam B. Jaffe, Josh Lerner and Scott Stern, The MIT Press.

[36] Motta, M., 2004, "Competition Policy: Theory and Practise, Cambridge University Press, UK.

[37] Nickell, S., 1996, "Competition and Corporate Performance", Journal of Political Economy vol. 104:4, 724-746.

[38] Norbäck, P. J. and Persson, L., 2005, "Privatization Policy in an International Oligopoly," Economica, 72, 288, 635-653.

[39] Norbäck, P. J. and Persson, L, 2009, "The Organization of the Innovation Industry: Entrepreneurs, Venture Capitalists, and Oligopolists". Journal of the European Economic Association, Vol. 7, No. 6, 2009, 1261-1290.

[40] OECD (2001a), OECD Science, Technology and Industry Scoreboard 2001, OECD, Paris.

[41] OECD (2001b), OECD Science, Technology and Industry Outlook. Drivers of Growth: Information Technology, Innovation and Entrepreneurship, OECD, Paris.

[42] OECD (2002a), OECD Small and Medium Enterprise Outlook, OECD, Paris.

[43] OECD (2002b), OECD Science, Technology and Industry Outlook, OECD, Paris.

[44] Salant, S, Switzer, S \& Reynolds, R , 1983, "Losses from horizontal merger: The effectsof an exogenous change in industry structure on Cournot-Nash equilibrium", Quarterly Journal of Economics, 48, 185-200.

[45] Schumpeter, J.,1912, "Theorie der Wirtschaftlichen, Entwicklung". Lipzig: Duncker\&Humbolt.

[46] Segal, I, 1999, Contracting with Externalities," Quarterly Journal of Economics, 114(2), May 1999, pp. 337-388

[47] Segal, I and M. Whinston (2007), "Antitrust in Innovative Industries", American Economic Review, vol. 97(5), pages 1703-1730, December.

[48] Sen, Debapriya and Yair Tauman, 2007, General licensing schemes for a cost-reducing innovation, Games and Economic Behavior, Volume 59, Issue 1, April 2007, Pages 163186. 
[49] Teece, D.J. (1987), "Profiting from technological innovation: Implications for integration, collaboration, licensing, and public policy," in D.J. Teece (ed.), The competitive challange: Strategies for industrial innovation and renewal, Ballinger: Cambridge (MA), pp.185-220.

[50] Vickers, John (1985), "Pre-emptive Patenting, Joint Ventures, and the Persistence of Oligopoly," International Journal of Industrial Organization, vol. 3, pp. 261-273.

[51] Vives, X., 2008, "Innovation and Competitive Pressure, "The Journal of Industrial Economics, 56, 3, 419-469. 


\section{A. Appendix}

\section{A.1. Proof of Lemma 1}

First, note that $b_{i} \geq \max v_{i l}, l=\{\mathrm{e}, \mathrm{i}\}$ is a weakly dominated strategy, since no incumbent will post a bid equal to or above its maximum valuation of obtaining the innovation and that firm $e$ will accept a bid iff $b_{i}>v_{e}$.

Inequality I1 Consider equilibrium candidate $b^{*}=\left(b_{1}^{*}, b_{2}^{*}, \ldots\right.$, yes $)$. Let us assume that incumbent $w \neq e$ is the incumbent that has posted the highest bid and obtains the assets and firm $s \neq d$ is the incumbent with the second highest bid.

Then, $b_{w}^{*} \geq v_{i i}$ is a weakly dominated strategy. $b_{w}^{*}<v_{i i}-\varepsilon$ is not an equilibrium since firm $j \neq w, e$ then benefits from deviating to $b_{j}=b_{w}^{*}+\varepsilon$, since it will then obtain the assets and pay a price lower than its valuation of obtaining them. If $b_{w}^{*}=v_{i i}-\varepsilon$, and $b_{s}^{*} \in\left[v_{i i}-\varepsilon, v_{i i}-2 \varepsilon\right]$, then no incumbent has an incentive to deviate. By deviating to no, the entrepreneur's payoff decreases since it foregoes a selling price exceeding its valuation, $v_{e}$. Accordingly, the entrepreneur has no incentive to deviate and thus, $b^{*}$ is a Nash equilibrium.

Let $b=\left(b_{1},,, b_{m}, n o\right)$ be a Nash equilibrium. Let incumbent $h$ be the incumbent with the highest bid. The entrepreneur will then say no iff $b_{h} \leq v_{e}$. But incumbent $j \neq e$ will have the incentive to deviate to $b^{\prime}=v_{e}+\varepsilon$ in stage 1 , since $v_{i e}>v_{e}$. This contradicts the assumption that $b$ is a Nash equilibrium.

Inequality I2 Consider equilibrium candidate $b^{*}=\left(b_{1}^{*}, b_{2}^{*}, \ldots, y\right)$. Then, $b_{w}^{*} \geq v_{i j}$ is a weakly dominated strategy. $b_{w}^{*}<v_{i j}-\varepsilon$ is not an equilibrium since firm $j \neq w, e$ then benefits from deviating to $b_{j}=b_{w}^{*}+\varepsilon$, since it will then obtain the assets and pay a price lower than its valuation of obtaining them. If $b_{w}^{*}=v_{i i}-\varepsilon$, and $b_{s}^{*} \in\left[v_{i i}-\varepsilon, v_{i i}-2 \varepsilon\right]$, then no incumbent has an incentive to deviate. By deviating to $n o$, the entrepreneur's payoff decreases since it foregoes a selling price exceeding its valuation, $v_{e}$. Accordingly, the entrepreneur has no incentive to deviate and thus, $b^{*}$ is a Nash equilibrium.

Consider the equilibrium candidate $b^{* *}=\left(b_{1}^{* *}, b_{2}^{* *}, \ldots, n o\right)$. Then, $b_{w}^{*} \geq v_{i e}$ is not an equilibrium since the entrepreneur would then benefit by deviating to yes. If $b_{w}^{*} \leq v_{e}$, then no incumbent has an incentive to deviate. By deviating to yes, the entrepreneur's payoff decreases since it then sells its assets at a price below its valuation, $v_{e}$. The entrepreneur has no incentive to deviate and thus, $b^{* *}$ is a Nash equilibrium.

Inequality I3 Consider the equilibrium candidate $b^{*}=\left(b_{1}^{*}, b_{2}^{*}, \ldots, y e s\right)$. Then, $b_{w}^{*} \geq v_{i i}$ is a weakly dominated strategy. $b_{w}^{*}<v_{i i}-\varepsilon$ is not an equilibrium since firm $j \neq w, e$ then benefits from deviating to $b_{j}=b_{w}^{*}+\varepsilon$, since it will then obtain the assets and pay a price lower than its valuation of obtaining them. If $b_{w}^{*}=v_{i i}-\varepsilon$, and $b_{s}^{*} \in\left[v_{i i}-\varepsilon, v_{i i}-2 \varepsilon\right]$, then no incumbent has an incentive to deviate. By deviating to no, the entrepreneur's payoff decreases, since it foregoes a selling price exceeding its valuation, $v_{e}$. Accordingly, the entrepreneur has no incentive to deviate and thus, $b^{*}$ is a Nash equilibrium.

Let $b=\left(b_{1}, \ldots, b_{m}, n o\right)$ be a Nash equilibrium. The entrepreneur will then say no iff $b_{h} \leq v_{e}$. But incumbent $j \neq e$ will then have the incentive to deviate to $b^{\prime}=v_{e}+\varepsilon$ in stage 1 , since 
$v_{i e}>v_{e}$. This contradicts the assumption that $b$ is a Nash equilibrium.

Inequality I4 Consider the equilibrium candidate $b^{*}=\left(b_{1}^{*}, b_{2}^{*}, \ldots\right.$, yes $)$. Then, $b_{w}^{*}>v_{e}$ is not an equilibrium since firm $w$ would then benefit from deviating to $b_{w}=v_{e}$. $b_{w}^{*}<v_{e}$ is not an equilibrium, since the entrepreneur would then not accept any bid. If $b_{w}^{*}=v_{e}-\varepsilon$, then firm $w$ has no incentive to deviate. By deviating to $b_{j}^{\prime} \leq b_{w}^{*}$, firm $j$ 's, $j \neq w, e$, payoff does not change. By deviating to $b_{j}^{\prime}>b_{w}^{*}$, firm $j$ 's payoff decreases since it must pay a price above its willingness to pay $v_{i i}$. Accordingly, firm $j$ has no incentive to deviate. By deviating to $n o$, the entrepreneur's payoff decreases since it foregoes a selling price above its valuation, $v_{e}$. Accordingly, the entrepreneur has no incentive to deviate and thus, $b^{*}$ is a Nash equilibrium.

Let $b=\left(b_{1},,, b_{m}\right.$, yes $)$ be a Nash equilibrium. If $b_{w} \geq v_{i i}$, then firm $w$ will have the incentive to deviate to $b^{\prime}=b_{w}-\varepsilon$. If $b_{w}<v_{i i}$, the entrepreneur will have the incentive to deviate to no, which contradicts the assumption that $b$ is a Nash equilibrium.

Let $b=\left(b_{1}, \ldots, b_{m}, n o\right)$ be a Nash equilibrium. The entrepreneur will then say no iff $b_{h} \leq v_{e}$. But incumbent $j \neq d$ will have the incentive to deviate to $b^{\prime}=v_{e}+\varepsilon$ in stage 1 since $v_{i e}>v_{e}$, which contradicts the assumption that $b$ is a Nash equilibrium.

Inequalities I5 or I6 Consider the equilibrium candidate $b^{*}=\left(b_{1}^{*}, b_{2}^{*}, \ldots, n o\right)$ where $b_{j}^{*}<v_{e}$ $\forall j \in J$. It then directly follows that no firm has an incentive to deviate and thus, $b^{*}$ is a Nash equilibrium.

Then, note that the entrepreneur will accept a bid iff $b_{j} \geq v_{e}$. But $b_{j} \geq v_{e}$ is a weakly dominating bid in these intervals since $v_{e}>\max \left\{v_{i i}, v_{i e}\right\}$. Thus, the assets will not be sold in these intervals.

\section{A.2. The Cournot Differentiated Product (CDP) model}

Proof of Lemma 3 Note that reduced-form profits can be written as $\pi_{h}(l)=\left[P_{h}(l)-c_{h}\right] q_{h}^{*}(l)=$ $\left[q_{h}^{*}(l)\right]^{2}$ since $P_{h}-c_{h}=q_{h}^{*}(l)$ from (3.1). It is straightforward to show that:

$$
\begin{gathered}
q_{A}^{*}(i)=\frac{\Lambda(2-\gamma)+\bar{k}(\gamma(m-2)+2)}{(m \gamma+2)(2-\gamma)}, \quad q_{N}^{*}(i)=\frac{\Lambda(2-\gamma)-\gamma \bar{k}}{(m \gamma+2)(2-\gamma)} \\
q_{e}^{*}(e)=\frac{\Lambda(2-\gamma)+\bar{k}(\gamma(m-1)+2)}{[(m+1) \gamma+2](2-\gamma)}, \quad q_{N}^{*}(e)=\frac{\Lambda(2-\gamma)-\gamma \bar{k}}{[(m+1) \gamma+2](2-\gamma)},
\end{gathered}
$$

where $\Lambda \equiv a-c$.

Proof part (i): By calculation $\left.\frac{d \pi_{N}(i)}{d \gamma}\right|_{\gamma=0}=-\frac{1}{4}(\bar{k}+(m-1) \Lambda) \Lambda<0$. Let us then show that $\frac{d \pi_{N}(l)}{d \gamma}<0$. We first show that there exists no minimum $\gamma_{N}^{\min } \in[0,1]$ such that $\left.\frac{d \pi_{N}(l)}{d \gamma}\right|_{\gamma=\gamma_{N}^{\min }}=0$. Solve for $\bar{k}$ as a function $\gamma$ which fulfills $\frac{d \pi_{N}(l)}{d \gamma}=0$. Denote this by $\varphi_{N}(\gamma)$ and note that $\varphi_{N}(\gamma)=-\frac{(m-1) \Lambda(2-\gamma)^{2}}{\left(m \gamma^{2}-\gamma^{2}+4\right)}<0$ since $\gamma \in[0,1]$. Hence, since $\bar{k}>0$, there exists no $\varphi_{N}(\gamma)$ such that $\frac{d \pi_{N}(l)}{d \gamma}=0$. Since $\left.\frac{d \pi_{N}(l)}{d \gamma}\right|_{\gamma=0}<0$, this implies that $\frac{d \pi_{N}(l)}{d \gamma}<0, \forall \gamma \in[0,1]$. 


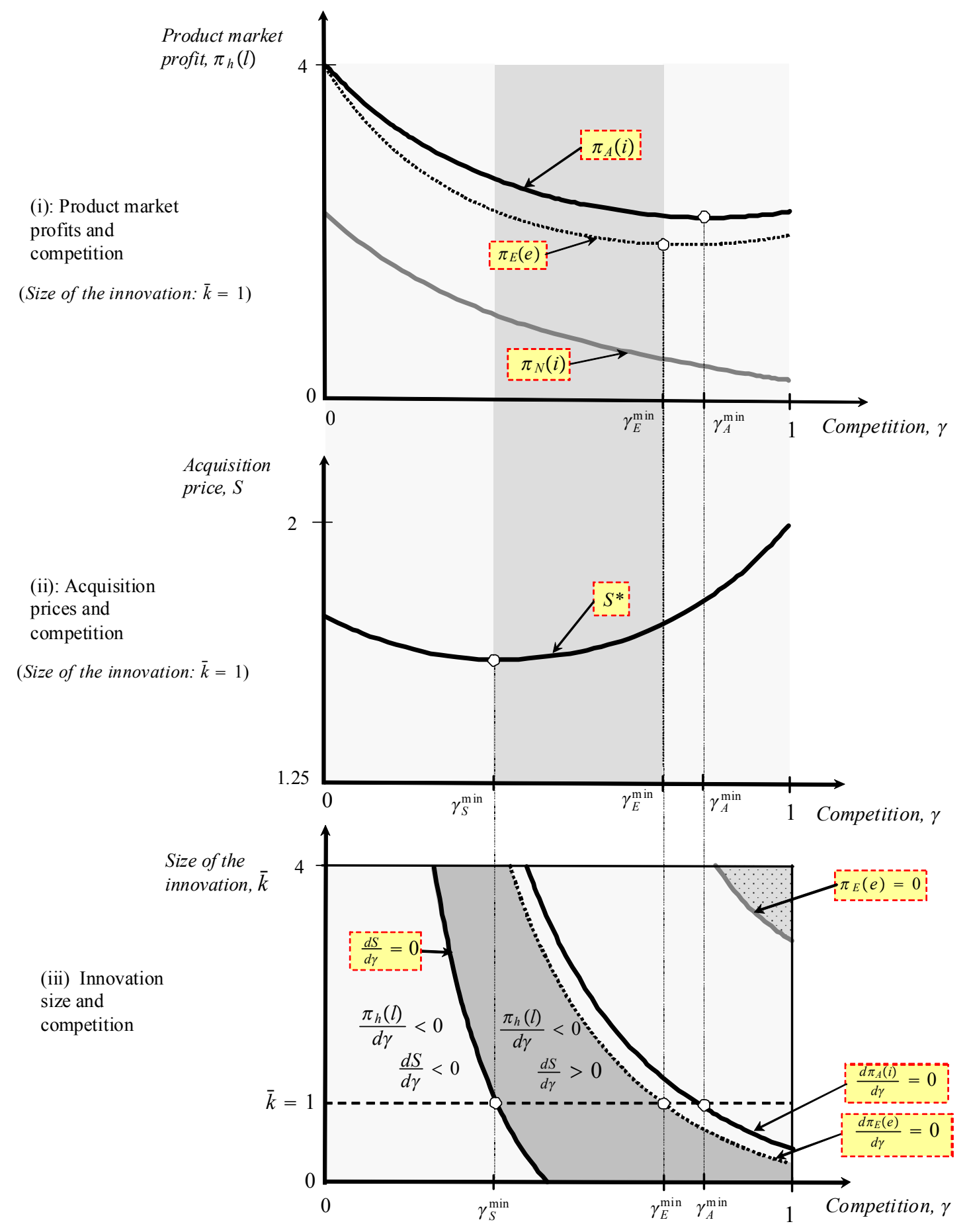

Figure A.1: Profits and sales price in the DPC model as a function of product substitutability. Parameter values at $\Lambda=3, m=3 . \bar{k}=1$ in panels (i) and (ii). 
Proof part (ii): We need to show that $\pi_{h}(l)$ for $h=A, e$ is strictly convex in $\gamma$ with a unique minimum $\gamma_{h}^{\min }$, where $\gamma_{e}^{\min }<\gamma_{A}^{\min }$. Solve for $\bar{k}$ as a function $\gamma$ which fulfills $\frac{d \pi_{h}(l)}{d \gamma}=0$. Denote this by $\varphi_{h}(\gamma)$ (this line is marked by $\frac{d \pi_{h}(l)}{d \gamma}=0$ in Figure A.1(iii)) and note that $\varphi_{A}(\gamma)=$ $\frac{(2-\gamma)^{2} \Lambda}{(m \gamma-2 \gamma+4) \gamma}>\frac{(2-\gamma)^{2} \Lambda}{((m+1) \gamma-2 \gamma+4) \gamma}=\varphi_{E}(\gamma)>0, \varphi_{h}(0)=\infty$ and $\varphi_{A}(1)=\frac{4 \Lambda}{(m+2)}>\frac{4 \Lambda}{(m+3)}=\varphi_{e}(1)>$ $0, \frac{d \varphi_{A}(\gamma)}{d \gamma}=-4(2-\gamma) \Lambda \frac{2-\gamma+m \gamma}{(m \gamma-2 \gamma+4)^{2} \gamma^{2}}<0$ and that $\frac{d \varphi_{e}(\gamma)}{d \gamma}=-4(2-\gamma) \Lambda \frac{2-\gamma+(m+1) \gamma}{((m+1) \gamma-2 \gamma+4)^{2} \gamma^{2}}<0$. Since $\varphi_{h}(\gamma)$ is continuous and monotonically decreasing in $\gamma$, it follows that for each $\bar{k}>0$, there exists a unique $\gamma_{h}^{\min } \in[0,1]$, such that (a) $\frac{d \pi_{h}(l)}{d \gamma}<0$ for $\gamma \in\left[0, \gamma_{h}^{\min }\right)$ and $\frac{d \pi_{h}(l)}{d \gamma}>0$ for $\gamma \in\left(\gamma_{h}^{\min }, 1\right)$ and (b) $\gamma_{e}^{\min }<\gamma_{A}^{\min }$. Since $\left.\frac{d \pi_{A}(i)}{d \gamma}\right|_{\gamma=0}=-\frac{1}{4}(\bar{k}+\Lambda)(m-1) \Lambda<0$ and $\left.\frac{d \pi_{e}(e)}{d \gamma}\right|_{\gamma=0}=-\frac{1}{4}(\bar{k}+\Lambda) \Lambda m<0 \frac{d \pi_{h}(l)}{d \gamma} \gamma=0<0$, this implies that $\pi_{h}(l)$ for $h=A, e$ is strictly convex in $\gamma$ with a unique minimum $\gamma_{h}^{\min }$, where $\gamma_{e}^{\min }<\gamma_{A}^{\min }$.

Proof part (iii): We need to show that for $m=2, \frac{d S}{d \gamma}>0$, while for $m>2, S=v_{i i}$ is strictly convex in $\gamma$ with a unique minimum $\gamma_{S}^{\min }<\gamma_{e}^{\min }<\gamma_{A}^{\min }$. Note that $S^{*}=v_{i i}=\pi_{A}(i)-\pi_{N}(i)$. (a) Under duopoly, $m=2, \frac{d \pi_{A}(i)}{d \gamma}-\frac{d \pi_{N}(i)}{d \gamma}=2 \frac{(\bar{k}+2 \Lambda) \bar{k} \gamma}{(\gamma+2)^{2}(2-\gamma)^{2}}>0$. (b) Beyond duopoly, $m>2$, we have $\left.\frac{d S}{d \gamma}\right|_{\gamma=0}=-\frac{1}{4}(m-2) \Lambda \bar{k}<0$. Solve for $\bar{k}$ as a function $\gamma$ which fulfills $\frac{d S}{d \gamma}=0$. Denote this by $\varphi_{S}(\gamma)$ (this line is marked by $\frac{d S}{d \gamma}=0$ in Figure A.1(iii)) and note that

$$
\varphi_{S}(\gamma)=\left\{\begin{array}{cc}
2 \frac{(m+\gamma-m \gamma-2)(2-\gamma) \Lambda}{\left(4 m+3 \gamma-4 m \gamma+m^{2} \gamma-6\right) \gamma}>0 & \text { iff } \gamma<\frac{m-2}{m-1}<1 \\
0 & \text { iff } \gamma>\frac{m-2}{m-1}<1
\end{array},\right.
$$

where $4 m+3 \gamma-4 m \gamma+m^{2} \gamma-6=\gamma(m-1)(m-3)+2(2 m-3)>0$. Note also that $\frac{d \varphi_{S}(\gamma)}{d \gamma}=$ $\frac{2 \Lambda(m-2)(m \gamma-\gamma+2)(3 m \gamma-3 \gamma-4 m+6)}{\left(4 m+3 \gamma-4 m \gamma+m^{2} \gamma-6\right)^{2} \gamma^{2}}<0$ since $-4 m+3 m \gamma+6-3 \gamma=(2-\gamma)(-2 m+3)+\gamma m<0$ since $\gamma \in[0,1]{ }^{28}$. By calculation, we have $\varphi_{E}(\gamma)-\varphi_{S}(\gamma)=(2-\gamma) \Lambda \frac{2 m \gamma+4-\gamma^{2}+m^{2} \gamma^{2}}{(m \gamma-\gamma+4) \gamma\left(4 m+3 \gamma-4 m \gamma+m^{2} \gamma-6\right)}>$ 0 and hence from A.2 $\varphi_{S}(\gamma)<\varphi_{E}(\gamma)<\varphi_{A}(\gamma)$. Since $\varphi_{S}(\gamma)$ is a monotonous function of $\gamma$, it follows that for each $\bar{k}>0$, there exists a unique $\gamma_{h}^{\min } \in[0,1]$ such that (a) $\frac{d S^{*}}{d \gamma}<0$ for $\gamma \in\left[0, \gamma_{S}^{\min }\right)$ and $\frac{d S}{d \gamma}>0$ for $\gamma \in\left(\gamma_{S}^{\min }, 1\right)$. Since $\left.\frac{d S^{*}}{d \gamma}\right|_{\gamma=0}<0$, this implies that $S^{*}$ is strictly convex in $\gamma$ with a unique minimum $\gamma_{S}^{\min }<\gamma_{e}^{\min }<\gamma_{A}^{\min }$.

\section{A.2.1. Illustration with Bertrand competition}

First, invert the inverse demand function in $P_{h}(q)$ into direct demand $q_{h}(p)$ where $p=\left(p_{h}, p_{-h}\right)$. It can be shown that:

$$
\begin{array}{ccc}
q_{A}(\mathbf{p}, i)=\frac{a(1-\gamma)+[(2-m) \gamma-1] P_{1}+(m-1) \gamma P_{2}}{(1-\gamma)[\gamma(m-1)+1]} & q_{E}(\mathbf{p}, e)=\frac{a(1-\gamma)+[(2-m) \gamma-1] P_{1}+(m-1) \gamma P_{2}}{(1-\gamma)[\gamma(m-1)+1]} \\
q_{N}(\mathbf{p}, i)=\frac{a(1-\gamma)+\gamma P_{1}-P_{2}}{(1-\gamma)[\gamma(m-1)+1]} & , & q_{N}(\mathbf{p}, e)=\frac{a(1-\gamma)+\gamma P_{1}-P_{2}}{(1-\gamma)[\gamma(m-1)+1]}
\end{array} .
$$

Then, rewrite firm $h$ 's profit as $\pi_{h}=\left(p_{h}-c_{h}\right) q_{h}(p)$. Making use of (A.4) and maximizing $\pi_{h}$ with regard to $p_{h}$ and solving for each ownership structure $l=e, i$, it is straightforward to derive the Nash-Bertrand price vector, $p^{*}(l)$. Inserting into (A.4) and using the profit $\pi_{h}$, we can derive

\footnotetext{
${ }^{28}$ For $(2-\gamma)(-2 m+3)+\gamma m<0$, we need to have $\gamma<\gamma^{\text {crit }}=\frac{2}{3} \frac{2 m-3}{m-1}$. Note that $\lim _{m \rightarrow \infty} \gamma^{\text {crit }}=\frac{2}{3} \frac{2-3 / m}{1-1 / m}=$ $\frac{4}{3}>1$. This implies that $\gamma<\gamma^{\text {crit }}$ is always fulfilled since $\gamma \in[0,1]$ and hence, $(2-\gamma)(-2 m+3)+\gamma m<0$.
} 


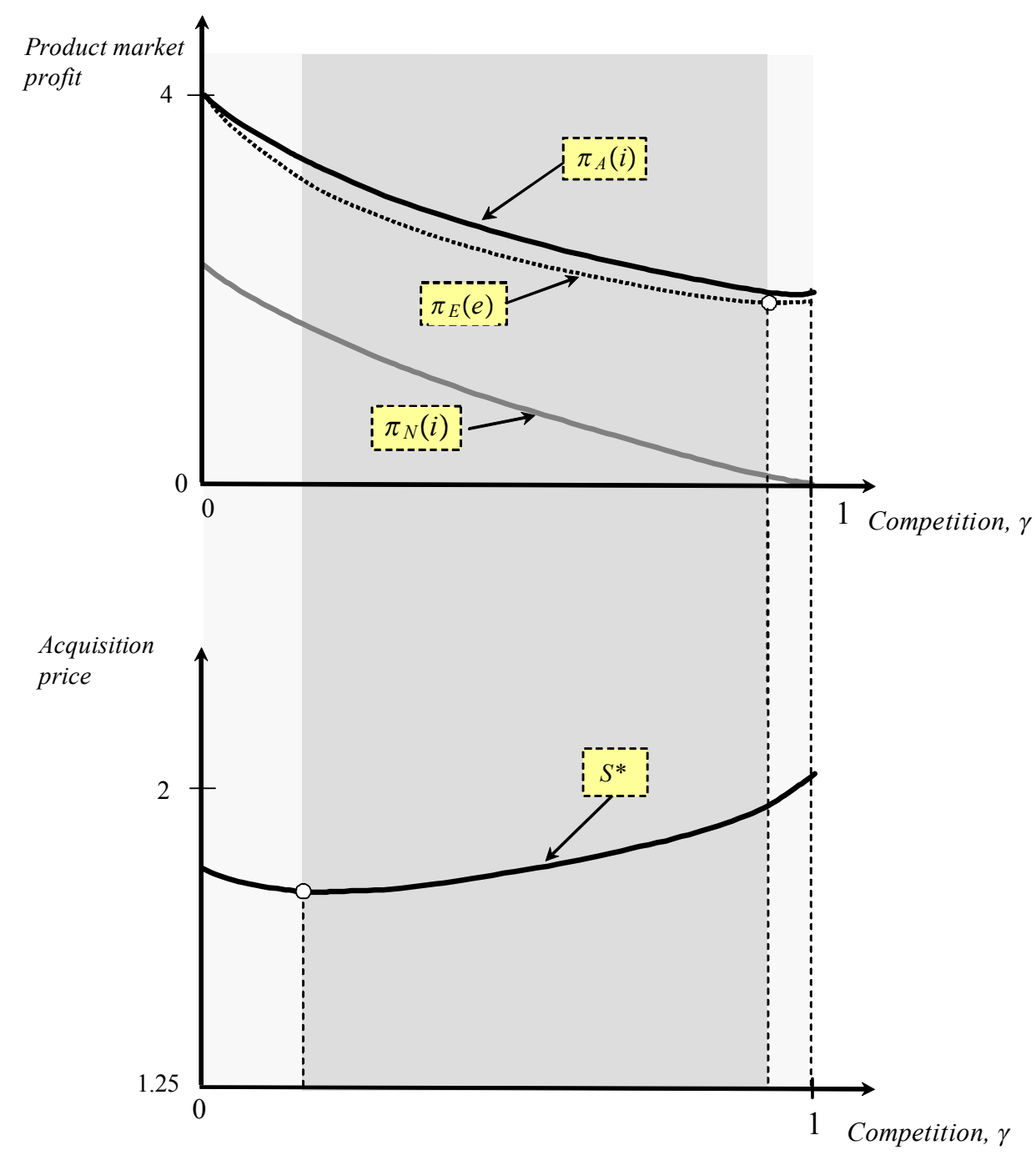

Figure A.2: Profits and sales price as a function of product substitatbility under Bertrand competition. Parameter values at $\Lambda=3, m=3$ and $\bar{k}=1$.

a reduced-form profit $\pi_{h}(l)=\left(p_{h}^{*}-c_{h}\right) q_{h}\left(p^{*}\right)$ which can once more be examined by changing the product substitutability parameter, $\gamma$. As illustrated in Figure A.2, the results are qualitatively the same as when assuming identical parameter values as in Figure A.1, which assumes Cournot competition. Through this example, Lemma 3 also holds for Bertrand competition.

\section{A.2.2. Proof of Lemma 5}

Let $F=f=0$ and note that $\gamma=0 v_{i i}-v_{e}=v_{i e}-v_{e}=-\frac{1}{4} \Lambda^{2}<0$. (a) We first derive the solution for all parameter values fulfilling the equation $v_{i i}-v_{e}=0$. To this end, we solve the equation for $\frac{\bar{k}}{\Lambda}(\gamma)$. We then find two solutions: $\frac{\bar{k}_{1}}{\Lambda}=\frac{2-\gamma}{\gamma}>1$ and $\frac{\bar{k}_{2}}{\Lambda}=(2-\gamma) \frac{m \gamma-\gamma+2}{\gamma(6-\gamma+3 m \gamma)}$. Since $\frac{\bar{k}_{1}}{\Lambda}<1$ is required for $q_{N}^{*}(i) \geq 0$, only $\bar{k}_{2}$ is admissible. Let $\frac{\bar{k}_{2}}{\Lambda}=\varphi^{P E}(\gamma)$. Then, note that $\frac{\partial \varphi^{P E}(\gamma)}{\partial \gamma}=-2 \frac{\gamma(12 m-4)+\gamma^{2}\left(3 m^{2}-4 m-1\right)+12}{(3 m \gamma-\gamma+6)^{2} \gamma^{2}}<0, \varphi^{P E}(0)=\infty$, and $\varphi^{P E}(1)=\frac{m+1}{3 m+5}<1$. Since $\varphi^{P E}(\gamma)$ is continuous and monotonically decreasing in $\gamma$ and $v_{i i}(\gamma=0)-v_{e}(\gamma=0)<0$, it follows that for each $\frac{\bar{k}_{2}}{\Lambda}>0$, there exists a unique $\gamma^{P E}$ such that $v_{i i}>v_{e}$ for $\gamma>\gamma^{P E}$ and 


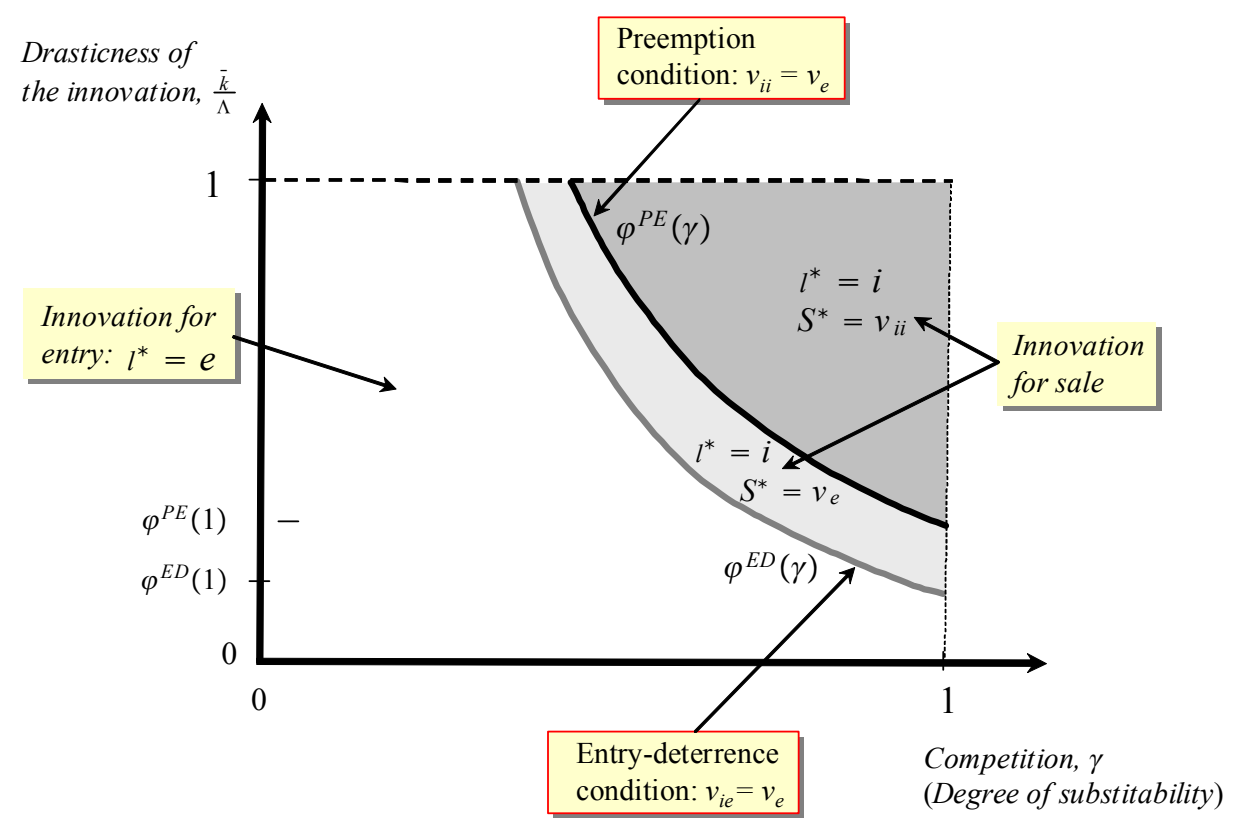

Figure A.3: Solving for innovation for sale and innovation for entry as a function of competition in the DPC model. The number of incumbents is set to $m=3$.

$v_{i i}<v_{e}$ for $\gamma<\gamma^{P E}$.

(b) We now derive the solution for all parameter values fulfilling the equation $v_{i e}-v_{e}=0$. To this end, we solve the equation for $\frac{\bar{k}}{\Lambda}(\gamma)$. We then find two solutions: $\frac{\bar{k}_{1}}{\Lambda}=\frac{2-\gamma}{\gamma}>1$ and $\frac{\bar{k}_{2}}{\Lambda}=(2-\gamma) \frac{-4 m \gamma^{2}+m^{2} \gamma^{2}+2 \gamma^{2}+4 m \gamma-8 \gamma+4}{\gamma\left(3 m^{2} \gamma^{2}+12 m \gamma-6 m \gamma^{2}+2 \gamma^{2}-12 \gamma+12\right)}$. Since $\frac{\bar{k}_{1}}{\Lambda}<1$ is required for $q_{N}^{*}(i) \geq 0$, only $\bar{k}_{2}$ is admissible. Let $\frac{\bar{k}_{2}}{\Lambda}=\varphi^{E D}(\gamma)$. Then, it can be shown that $\frac{\partial \varphi^{E D}(\gamma)}{\partial \gamma}<0, \varphi^{E D}(0)=\infty$, and $\varphi^{E D}(1)=\frac{m^{2}-2}{6 m+3 m^{2}+2}<1$. Since $\varphi^{E D}(\gamma)$ is continuous and monotonically decreasing in $\gamma$ and $v_{i e}(\gamma=0)-v_{e}(\gamma=0)<0$, it follows that for each $\frac{\bar{k}_{2}}{\Lambda}>0$ there exists a unique $\gamma^{E D}$ such that $v_{i e}>v_{e}$ for $\gamma>\gamma^{E D}$ and $v_{i e}<v_{e}$ for $\gamma<\gamma^{E D}$.

(c) Since $v_{i e}>v_{i i}$, it follows that $\varphi^{E D}(\gamma)$ is below and to the left of $\varphi^{P E}(\gamma)$.

(d) For $F>0$, we have $v_{e}=\pi_{E}(e)-F$. It then follows that increasing $F$ for $F \in\left[0, \pi_{E}(e)\right]$ will reduce $\varphi^{E D}(\gamma)$ and $\varphi^{P E}(\gamma)$ and, hence, $\gamma^{P E}$ and $\gamma^{E D}$ are decreasing in $F$.

(e) The above derived properties are then used to draw the curves in Figure A.3.

\section{A.2.3. Proof of Proposition 5}

First, note that $\Lambda(2-\gamma)-\gamma \bar{k}>0$ from $q_{N}^{*}(e)>0$ in (A.1). Using differentiation, we have $\frac{d \pi_{h}(l)}{d n}=-2 \frac{(2 \bar{k}(1-\gamma)+\Lambda(2-\gamma)+\bar{k} n \gamma)[\Lambda(2-\gamma)-\gamma \bar{k}] \gamma}{(n \gamma-\gamma+2)^{3}(2-\gamma)^{2}}<0$ for $h=A, E, \frac{d \pi_{N}(l)}{d n}=-2 \frac{(\Lambda(2-\gamma)-\gamma \bar{k})^{2} \gamma}{(n \gamma-\gamma+2)^{3}(\gamma-2)^{2}}$ and, finally, $\frac{d S}{d n}=-2 \frac{(\Lambda(2-\gamma)-\gamma \bar{k}) \bar{k} \gamma}{(n \gamma-\gamma+2)^{2}(2-\gamma 2)^{2}}<0$ hold in these intervals. It is straightforward to show that the same results hold when the number of firms $n$ is a discrete variable. 